Discussion Paper No. 1032

\title{
SECULAR STAGNATION IN AN ECONOMY WITH LAND
}

\author{
Matthias Schlegl
}

June 2018

The Institute of Social and Economic Research Osaka University

6-1 Mihogaoka, Ibaraki, Osaka 567-0047, Japan 


\title{
Secular Stagnation in an Economy with Land
}

\author{
Matthias Schlegl \\ JSPS International Research Fellow, Osaka University \\ Ph.D. Candidate, University of Munich \\ email: matthias.schlegl@econ.lmu.de
}

This Version: June 2018*

\begin{abstract}
I present a model of secular stagnation with land and infinitely-lived agents with wealth preferences. Land is the prime example of a non-producible productive asset and rules out a negative real interest rate in steady state. With standard wealth preferences, higher land prices stimulate consumption and full employment is always feasible in steady state unless the central bank follows a deflationary policy. In contrast, secular stagnation emerges as the unique equilibrium of the monetary economy if wealth preferences are insatiable. In contrast to conventional wisdom, it is very existence of land itself that prevents full employment from being feasible in this case. Increases in the inflation target are no longer effective in restoring full employment as stagnation is a real phenomenon. These conclusions hold if households require a risk premium on land. Then, a higher risk premium can restore full employment when wealth preferences are insatiable.
\end{abstract}

Keywords: Secular Stagnation, Wealth Preferences, Rational Bubbles, Land

JEL Classification: E31, E44

*I am grateful to Gerhard Illing, Jean-Baptiste Michau and Yoshiyasu Ono for helpful comments and suggestions. Financial support from the "JSPS Postdoctoral Fellowship for North American and European Researchers (Short-Term)" of the Japan Society for the Promotion of Science (JSPS) is gratefully acknowledged as is the Grants-in-Aid for Scientific Research (S) Humanities and Social Sciences (Social Sciences) 'Behavioral-Economic Analysis of Long-Run Stagnation (15H05728)' (2016-). 


\section{Introduction}

The term "secular stagnation" describes the persistent failure of an economy to produce at full capacity as a result of an oversupply of savings. Originally postulated by Hansen (1939) in the wake of the Great Depression, the hypothesis seemed to have lost its relevance in the post-war economic system as downturns were limited to short-lived recessions that could be sufficiently well addressed by monetary policy. However, the unexpected fall of Japan, the then second-largest economy, into decades of inadequate growth and particularly the sluggish recovery in most economies during the Great Recession have led to a resurrection of this idea, most famously by Summers (2013). ${ }^{1}$

The secular stagnation hypothesis relies on two claims. First, the natural rate of interest, which is the short-term interest rate consistent with full employment, has permanently declined into negative territory as a result of high desired savings and low investment demand. Economies hence overaccumulate capital. Second, the real return on savings cannot fall sufficiently to accommodate the decline of the natural rate as a consequence of the zero lower bound on the nominal interest rate and the commitment of central banks to maintain price stability. This mismatch results in an oversupply of savings, which depresses aggregate demand and prevents markets from clearing at full employment. Therefore, stagnation is a monetary phenomenon.

There is, however, a major objection to this argument. The existence of a non-producible productive asset prevents overaccumulation and restricts the real interest rate to be positive as shown by Homburg (1991). The argument is simple: An asset with positive rent payments and finite price has a strictly positive yield, which constitutes a real return. Excess savings can be invested into this asset, the natural rate of interest remains positive in steady state and secular stagnation does not occur. Land is the prime example of such an asset with high empirical relevance. According to Homburg (2014), land values exceed GDP and public debt in many major economies and land is almost as important as capital from a macroeconomic perspective. However most models of secular stagnation exclude the possibility of investment in land. ${ }^{2}$

I propose a theory of secular stagnation in an economy with land based on strong wealth preferences of households. Specifically, I extend the standard neoclassical growth model with infinitely-lived agents along the following dimensions.

\footnotetext{
${ }^{1}$ In fact, Summers (2014) argues that weak aggregate demand has been present in the United States for several decades but was masked by the stock market boom of the 1990s and the credit boom of the early 2000s, both of which initiated unsustainable consumption spending of households. Illing et al. (2017) formally show that credit booms can temporarily cure aggregate demand deficiency but come at the cost of more severe stagnation in the long-run due to the resulting debt overhang.

${ }^{2}$ The existence of equity also prevents overaccumulation of capital if the dividend on stocks is strictly positive. This is the case if labor is not an input factor in the production process as in Zhou (2013) or in case of imperfect financial markets that prevent negative dividend payments and stock dilution.
} 
First, I introduce wealth preferences of households. The idea of wealth accumulation for the sake of itself as an aspiration of human behavior has a long tradition in economic thought and is embraced among others in the works of Adam Smith, Karl Marx, Max Weber and John Maynard Keynes as described in great detail by Zou (1994), who refers to the concept as "spirit of capitalism". In addition, it can be related to behavioral factors like status concerns. Wealth preferences have first been formally introduced into the neoclassical growth model by Kurz (1968) and Bose (1971) and their implications are analyzed in several contributions. ${ }^{3}$ Wealth preferences create a strong desire for savings which lowers the natural interest rate below the time preference rate and potentially into negative territory. Preferences for wealth therefore present an alternative to the overlapping generations model that can also generate a negative real rate, as is well-known since Samuelson (1958). Recent contributions by Michaillat and Saez (2014) and Michau (2017) study similar models of secular stagnation based on wealth preferences. Ono $(1994,2015)$ offers a theory of stagnation based on the additional assumption that wealth preferences are insatiable. However, these papers do not account for the availability of a non-producible productive asset.

I extend these models by introducing land as a means of saving for households in addition to bonds, physical capital and money. Land is a non-producible asset in fixed supply and pays a positive rent. ${ }^{4}$ The land value affects the natural rate of interest via the wealth preference and its rental yield represent a strictly positive real return on savings, which rules out a negative real interest rate in steady state.

I also introduce money into the model via a money-in-the-utility framework, in which the central bank directly controls the nominal money supply. In addition, I impose a limit on nominal wage declines in periods of aggregate demand shortage to prevent a deflationary spiral. This friction is borrowed from Schmitt-Grohé and Uribe $(2016,2017)$ and results in a non-linear inflation process. ${ }^{5}$

What determines the value of land? Under what conditions does secular stagnation occur in steady state? And what is the role of monetary policy? I analyze these questions in both a neoclassical model with land and its extended monetary version. The analysis focuses primarily on the steady state properties of these models. The conclusions differ markedly depending on the nature of the preference for wealth.

\footnotetext{
${ }^{3}$ Bakshi and Chen (1996) and Smith (2001) study the implications of wealth preferences for asset pricing. Kumhof et al. (2015) explain the rise in inequality in recent decades in a model with wealth preferences of rich households. Michau et al. (2017) analyze their effects on the natural interest rate and the occurrence of rational bubbles in a model with infinitely-lived assets. Similarly, Kamihigashi (2008) and Zhou (2013, 2015) study rational equity bubbles in a model with wealth preferences.

${ }^{4}$ The constant supply property of land is one of the main reasons why it is typically omitted in standard growth models with technological progress. An exception is Nichols (1970), who incorporates land into a balanced growth model with land-augmenting technological progress.

${ }^{5}$ Similar nominal rigidities are used in other models of secular stagnation like Michau (2017), Eggertsson, Mehrotra, and Robbins (2017), Caballero and Farhi (2018) or Ono and Ishida (2014).
} 
With standard wealth preferences, the case for secular stagnation is substantially weakened by the introduction of land as investments in land absorb the oversupply of savings. Full employment prevails in the neoclassical model as increases in the land value stimulate household consumption and increase the natural interest rate into positive territory. In the monetary version of this model, secular stagnation could in principle occur in steady state. However, this requires quite restrictive assumptions. Specifically, the economy has to be deflationary at full capacity to rule out full employment. In addition, it requires that the real money stock does not affect the desire for savings via the wealth preference. Then, the real interest rate is determined solely in the real economy. In contrast, stagnation cannot occur if the real money stock is considered net wealth by households as increases in the money supply stimulate consumption until full employment is restored ${ }^{6}$ In addition, the land price always equals its fundamental value and rational land price bubbles cannot occur.

These conclusions change profoundly if the desire for wealth accumulation is insatiable. Specifically, I follow the literature initiated by Ono (1994) and assume a strictly positive lower bound on the marginal utility from wealth. Then, full employment cannot be maintained in steady state if the desire for savings is sufficiently strong and secular stagnation occurs. This steady state is not well-defined in the neoclassical economy, but uniquely determined in the monetary economy by the binding nominal wage rigidity. Stagnation persists even though households can invest in land at a positive real rate. In fact, it is the very existence of land that creates stagnation as it prevents the actual return on savings from falling sufficiently to clear markets at full employment. As households become sufficiently wealthy, their consumption ceases to be affected by further increases in wealth, which is why the natural interest rate can permanently remain below the return on savings. In addition, land price bubbles can occur.

Consequently, secular stagnation is a real phenomenon and increases in the inflation target are no longer effective in restoring full employment. The steady state with aggregate demand shortage is unique and multiple equilibria are ruled out. This is in contrast to monetary models of secular stagnation like Michau (2017) or Caballero and Farhi (2018), in which both stagnation and full employment steady states coexist for a sufficiently high money growth rate.

These findings continue to hold when households require a risk premium on land investments. Increases in the inflation target are only effective if the return on money, rather than the return on land, constrains the return on savings. With standard wealth preferences, an increase in the risk premium can prevent the economy from operating at full employment. In contrast, a higher risk premium can help to restore full employment when wealth preferences are insatiable.

\footnotetext{
${ }^{6}$ This mechanism would also restore full employment in Michau (2017). However, money is not part of net household wealth in the steady state of his model and hence does not affect the natural rate.
} 
Related Literature: This paper contributes to the growing literature on secular stagnation and offers a theory of stagnation based on the existence of a real asset, namely land. In contrast, stagnation is considered a monetary phenomenon throughout the literature starting with Keynes (1936), who argues in Chapter 17 of the General Theory that permanent demand shortage can exist as a steady state phenomenon in a monetary economy. ${ }^{7}$

In the liquidity trap literature, stagnation occurs temporarily following severe demand shocks that result in a negative natural rate of interest (see among others Eggertsson and Krugman, 2012; Eggertsson and Woodford, 2003; Krugman, 1998). As the zero lower bound and wellanchored inflation expectations prevent the real return on money from falling sufficiently, an oversupply of savings depresses demand. However, full employment is eventually restored even in the absence of policy measures.

In secular stagnation models, no natural recovery occurs because the natural interest rate is permanently negative as a result of structural factors. ${ }^{8}$ In standard infinitely-lived agent models the natural interest rate in steady state is determined by the positive time preference rate of the least impatient agent as shown by Becker (1980). Models of secular stagnation therefore rely on an overlapping generations framework or wealth preferences, both of which allow for a negative natural rate in steady state.

In Eggertsson, Mehrotra, and Robbins (2017), the natural rate is negative as a consequence of deleveraging shocks, demographic developments, inequality or a fall in the price of capital goods. Kocherlakota (2013) highlights the role of asset price declines that can worsen stagnation if labor markets are incomplete, while Caballero and Farhi (2018) show that a shortage of safe assets depresses the natural interest rate in a perpetual youth model. ${ }^{9}$ Alternatively, wealth preferences of households can result in a negative natural rate. Then, secular stagnation can occur in the steady state of a monetary economy as shown by Michaillat and Saez (2014) and Michau (2017). A related strand of stagnation models is based on the stronger assumption of insatiable wealth or liquidity preferences. Initiated by Ono (1994) and substantially extended by Ono and Ishida (2014), these contributions assume that there exists a strictly positive lower bound on the marginal utility from wealth. A limit on the feasible inflation rate, for example via a restrictive inflation target of the central bank, rules out full employment.

\footnotetext{
${ }^{7}$ A modern formalization of Chapter 17 is provided by Ono (2001) in a continuous dynamic optimization model in which stagnation occurs as a consequence of strong liquidity preferences of households.

${ }^{8}$ In Ono (2001) and Illing et al. (2017), it is not the zero lower bound but strong liquidity preferences that create a lower bound on the return on money holdings. Then stagnation can occur even at a positive natural rate of interest, but it remains a monetary phenomenon.

${ }^{9}$ The open economy versions of these secular stagnation models are analyzed in Eggertsson, Mehrotra, and Summers (2016) and Caballero, Farhi, and Gourinchas (2016). International considerations include the notion of a "global savings glut", postulated by Bernanke (2005). For an overview of these and other factors, see the VoxEU.org eBook edited by Baldwin and Teulings (2014).
} 
Yet, what most of these contributions omit is the importance of non-producible and productive real assets, like land. There are two notable exceptions though.

In Kocherlakota (2013), the existence of land also implies a strictly positive real rate in steady state, which can result in stagnation if the wage inflation rate does not adjust sufficiently in case of imperfect labor markets. Then, exogenous land price declines further reduce the labor input. However, once capital is introduced into the model, stagnation requires the stronger assumption that the real rate cannot fall below the time preferences rate of the household. In contrast, I do not require any exogenous assumptions on the real rate. All restrictions are derived from the No-Arbitrage condition in asset markets.

The perpetual youth model of Caballero and Farhi (2018) features a non-producible Lucas tree. However, the return on this asset includes a risk-premium in the stagnation equilibrium. It is then again the existence of money that accounts for stagnation as the inflation rate restricts the real return on the safe asset. In contrast, I show that secular stagnation can result from the existence of both money and land when there is an exogenous risk premium on land. ${ }^{10}$

As stagnation is typically a monetary phenomenon, a sufficiently large and credible increase in the inflation target or the money growth rate is a common remedy (see for example Caballero and Farhi, 2018; Eggertsson, Mehrotra, and Robbins, 2017; Michaillat and Saez, 2014; Michau, 2017). This lowers the return on money and can restore full employment. Then, both full employment and stagnation steady states can occur. In an economy with land, increases in the inflation target cease to affect the economy under stagnation and cannot restore full employment as stagnation is a real phenomenon.

The negative real rate in secular stagnation models implies that economies accumulate too much capital, a state known as dynamic inefficiency. ${ }^{11}$ Under this condition, a rise in government debt can be a Pareto improvement, as shown by Diamond (1965). In fact, Michau (2017) argues that public debt cannot be unsustainable under secular stagnation. Moreover, rational asset price bubbles can occur as analyzed by Tirole (1985). In this paper, dynamic efficiency is restored once land is available. However, land price bubbles can still occur and are not ruled out by the transversality condition when the marginal utility of wealth is bounded from zero either in absolute terms or relative to consumption as also shown by Ono (1994), Kamihigashi (2008) and Zhou (2013, 2015)

\footnotetext{
${ }^{10}$ In this paper, agents have perfect foresight, which excludes stagnation equilibria based on self-fulfilling expectations as in Benhabib et al. (2001). Secular stagnation results from fundamental factors.

${ }^{11}$ Empirical tests of dynamic inefficiency are imperfect as temporary shortfalls of the real rate below the growth rate are possible in a dynamically efficient economy as argued by Homburg (2014). In a seminal paper, Abel et al. (1989) compare capital income with investment expenses as a criterion for efficiency and conclude that all major economies are dynamically efficient. This result is challenged by Geerolf (2017) after adjusting the efficiency criterion for rent income from land.
} 


\section{A Neoclassical Economy with Land}

Throughout this paper, I assume perfect foresight and abstract from uncertainty and technological progress. Time is continuous and denoted by $t$. The model consists of homogeneous households and competitive firms, which produce the single output good using labor and capital. There is no government. I make two extensions to the standard neoclassical model. First, households have preferences for wealth. Second, there is the possibility of investment in land.

\subsection{Asset Markets and the Real Return on Savings}

There are three assets in the neoclassical model: Bonds $b_{t}$, physical capital $K_{t}$ and land $H_{t}$. All of them serve as a store of value for households to transfer income over time.

Bonds are financial claims between households that yield a real return of $r_{t}$. Financial markets are perfect and there are no asymmetric information or contract enforcement problems. Bond market equilibrium requires $b_{t}=0$ as bonds are in zero net supply.

Physical capital is an input in the production process. It is owned by households, who rent it at price $R_{t}$ to firms. Capital depreciates at rate $\delta>0$. One unit of output can be transformed into one unit of consumption or one unit of investment and there are no adjustment costs. Therefore, the relative price of capital is one. ${ }^{12}$ The return on capital $r_{t}^{K}$ is then given by

$$
r_{t}^{K}=R_{t}-\delta
$$

Land is a non-producible productive asset. Unlike physical capital, land cannot be produced and does not depreciate. It is in fixed supply, normalized to $H_{t}=1$, and trades at real price $q_{t}$. Each unit of land pays a real rent $z>0$ to its owner, which is exogenous. Households can freely dispose of land, which implies that its price cannot become negative, i.e. $q_{t} \geq 0$. The return on land $r_{t}^{L}$ consists of a rental yield and potential capital gains or losses with

$$
r_{t}^{L}=\frac{\dot{q}_{t}}{q_{t}}+\frac{z}{q_{t}}
$$

Consider the decomposition of the land price $q_{t}$ into a fundamental component $q_{t}^{F}$ and a bubble component $q_{t}^{B}$, i.e.

$$
q_{t}=q_{t}^{F}+q_{t}^{B},
$$

\footnotetext{
${ }^{12}$ If investment is irreversible, we have $\dot{K}_{t}+\delta K_{t} \geq 0$. Then, the price of capital equals one whenever investment is positive, but it can drop below one once this constraint is binding. Changes in the price of capital then affect the return on capital, which is analyzed in Michau (2017). I abstract from this occasionally binding constraint as I focus on steady state analysis, in which investment is strictly positive due to depreciation. The same holds during the adjustment dynamics if the initial capital stock is below the steady state level.
} 
where the fundamental price is associated with rent payments and the bubble is a speculative price component, which is not backed by claims on income. The fundamental return is given by $r_{t}^{L}$ in (2) whereas the return on the bubble equals the capital gain or loss given by

$$
r_{t}^{B}=\frac{\dot{q}_{t}^{B}}{q_{t}^{B}}
$$

Equilibrium in the bond market, the market for physical capital and the market for land requires the equalization of returns across these assets. ${ }^{13}$ If bubbles exist, the bubble component has to grow with this rate as well, which is a standard requirement in the literature (see Tirole, 1985). This is formalized in the No-Arbitrage condition

$$
r_{t}=r_{t}^{K}=r_{t}^{L}\left(=r_{t}^{B}\right)
$$

where $r_{t}^{K}, r_{t}^{L}$ and $r_{t}^{B}$ are defined in (1), (2) and (4) respectively. Condition (5) implies that households are indifferent between bonds, physical capital and investment in land as a means of savings in equilibrium. All assets yield the same real return, which I will denote by $r_{t}^{S}$. This return determines the actual incentives of households to save.

\subsection{Competitive Firms}

Firms rent physical capital $K_{t}$ from households at rental price $R_{t}$ and employ labor $L_{t}$ at real wage $w_{t}$. They produce output $Y_{t}$ with the neoclassical production function

$$
Y_{t}=F\left(K_{t}, L_{t}\right)
$$

which exhibits constant returns to scale and fulfills the standard assumptions of strictly positive and declining marginal products of both factors. Let $k_{t}=K_{t} / L_{t}$ and $y_{t}=Y_{t} / L_{t}$ denote the capital stock per worker and output per worker respectively. Using (6), I rewrite output per worker as $y_{t}=F\left(k_{t}, 1\right)=f\left(k_{t}\right)$ with $f^{\prime}\left(k_{t}\right)>0$ and $f^{\prime \prime}\left(k_{t}\right)<0$.

Firms take $w_{t}$ and $R_{t}$ as given. In competitive factor markets, capital and labor are paid their marginal products, which implies that the rental price and the real wage are given by

$$
\begin{gathered}
R_{t}=F_{K}\left(K_{t}, L_{t}\right)=f^{\prime}\left(k_{t}\right) \\
w_{t}=F_{L}\left(K_{t}, L_{t}\right)=f\left(k_{t}\right)-k_{t} f^{\prime}\left(k_{t}\right)
\end{gathered}
$$

\footnotetext{
${ }^{13}$ The models of Caballero, Farhi, and Gourinchas (2016) and Caballero and Farhi (2018) also assume a nonproducible productive asset. However, the return on this asset can include a premium in the presence of aggregate risk depending on the marginal investor. I discuss the case of a risk premium in section 5 .
} 
Since the rental price always equals the marginal product of capital, the return on physical capital $r_{t}^{K}$ is given by its net marginal product. Using (7), $r_{t}^{K}$ in (1) is rewritten as

$$
r_{t}^{K}=f^{\prime}\left(k_{t}\right)-\delta
$$

By the No-Arbitrage condition (5), this return equals the real rate on bonds and the return on land $r_{t}^{L}$. Hence, (9) constitutes the actual real return on savings $r_{t}^{S}$ for households. ${ }^{14}$

\subsection{Households and the Natural Rate of Interest}

There is a mass one of identical and infinitely-lived households and no population growth. Households own physical capital, which they rent to firms. Each household is endowed with one unit of labor $L_{t}$, which is supplied inelastically at wage $w_{t}$. Therefore, $L_{t}=1$ represents full employment. Households can save via bonds $b_{t}$, investments in physical capital $K_{t}$ or investment in land at price $q_{t}$. Hence, total real wealth $a_{t}$ is decomposed as

$$
a_{t}=b_{t}+K_{t}+q_{t} H_{t}
$$

Households receive wage income and interest or rental income on their investments. This income is used to finance consumption spending $c_{t}$. Real wealth evolves as

$$
\dot{a}_{t}=r_{t} a_{t}+\left(r_{t}^{K}-r_{t}\right) K_{t}+\left(r_{t}^{L}-r_{t}\right) q_{t} H_{t}-c_{t}+w_{t} L_{t}
$$

By the No-Arbitrage condition (5), all assets have to yield the same return in equilibrium. Then, (11) simplifies to

$$
\dot{a}_{t}=r_{t} a_{t}-c_{t}+w_{t} L_{t}
$$

The representative household has preferences over consumption and wealth. His lifetime utility is given by

$$
U_{0}=\int_{0}^{\infty}\left[u\left(c_{t}\right)+v\left(a_{t}\right)\right] e^{-\rho t} d t
$$

where $\rho>0$ is the time preference rate. Utility $u(c)$ satisfies the standard assumptions $u^{\prime}(c)>0$, $u^{\prime \prime}(c)<0, \lim _{c \rightarrow 0} u^{\prime}(c)=\infty$ and $\lim _{c \rightarrow \infty} u^{\prime}(c)=0$. In contrast, the desire for wealth accumulation is insatiable. Specifically, I follow the literature initiated by Ono (1994) and assume

$$
v^{\prime}(a)>0, \quad v^{\prime \prime}(a) \leq 0, \quad \lim _{a \rightarrow 0} v^{\prime}(a)=v_{0}, \quad \lim _{a \rightarrow \infty} v^{\prime}(a)=\beta>0 .
$$

\footnotetext{
${ }^{14}$ Note that the same result is obtained when firms own the capital stock directly. In this case, households are shareholders and receive dividend income equal to firm profits. As firms have to replace the depreciated capital stock, the net marginal product still determines the return on household savings $r_{t}^{S}$.
} 
There exists a lower bound $\beta$ on the marginal utility from wealth, which stays positive even as wealth becomes infinitely high. This assumption is borrowed from behavioral economics and related to status preferences as discussed in Murota and Ono (2011). ${ }^{15}$

Maximizing (13) subject to (12) yields the Euler Equation and the transversality condition as

$$
\begin{gathered}
\eta_{c} \frac{\dot{c}_{t}}{c_{t}}=r_{t}-\rho+\frac{v^{\prime}\left(a_{t}\right)}{u^{\prime}\left(c_{t}\right)}, \quad \text { where } \eta_{c} \equiv-\frac{u^{\prime \prime}\left(c_{t}\right) c_{t}}{u^{\prime}\left(c_{t}\right)}, \\
\lim _{t \rightarrow \infty} a_{t} u^{\prime}\left(c_{t}\right) e^{-\rho t}=0 .
\end{gathered}
$$

Compared to the standard Euler Equation, wealth preferences create an incentive for savings in addition to the impatience motive. I define the natural rate of interest $r_{t}^{N}$ as the real interest rate that clears the goods market at full employment. It is given by (14) with $L_{t}=1$. As saving becomes a virtue by itself, goods market clearing requires a real rate below the time preference rate. The natural rate can even become negative if the preference for wealth is sufficiently strong.

Finally, the transversality condition (15) implies that household wealth cannot grow at a rate greater or equal to $\rho$ in a stationary steady state.

\subsection{Market Clearing Conditions}

The real wage perfectly adjusts to clear the labor market with $L_{t}=1$ at full employment. The No-Arbitrage condition (5) implies bond market clearing with $b_{t}=0$, land market clearing with $H_{t}=1$ and equilibrium in the market for physical capital. Then real wealth is given by

$$
a_{t}=K_{t}+q_{t}=k_{t} L_{t}+q_{t}
$$

Aggregate supply consists of output $Y_{t}$ and the rent $z$ from land. Aggregate demand equals consumption demand $c_{t}$ and gross investment in capital $\dot{K}_{t}+\delta K_{t}$. Goods market clearing requires

$$
Y_{t}+z=c_{t}+\dot{K}_{t}+\delta K_{t}
$$

which can be rearranged and expressed in per worker terms as

$$
\dot{K}_{t}=\dot{k}_{t} L_{t}+k_{t} \dot{L}_{t}=\left[f\left(k_{t}\right)-\delta k_{t}\right] L_{t}+z-c_{t} .
$$

Under full employment, it holds that $L_{t}=1$ and $\dot{L}_{t}=0$. Then $k_{t}=K_{t}$ and $\dot{K}_{t}=\dot{k}_{t}$. In the next section, I analyze the conditions, under which the full employment steady state exists.

\footnotetext{
${ }^{15}$ Ono, Ogawa, et al. (2004) offer empirical support for the insatiability of preferences for monetary wealth based on quarterly data in Japan using parametric and non-parametric methods.
} 


\section{Analysis of the Neoclassical Economy}

The neoclassical model economy is characterized by the Euler Equation (14), the wealth composition (16), the return on physical capital (9), the return on land investment (2), the goods market clearing condition (18) and the No-Arbitrage condition (5) together with the transversality condition (15) for any given initial value of capital $K_{0}>0$. In case of a bubbly equilibrium, equations (3) and (4) also apply for a given initial bubble value $q_{0}^{B}>0$. Under full employment, it holds that $L_{t}=1$ and consequently $K_{t}=k_{t}$. Each stationary steady state is characterized by $\dot{c}_{t}=0$ and $\dot{k}_{t}=0$.

The feasibility of full employment in steady state is determined by the actual real return on savings $r^{S}$ and the natural rate of interest $r^{N}$. The actual return on savings follows from the No-Arbitrage condition (5), which requires the equalization of the real returns of all available assets. Using the definitions of the returns on land in (2) and capital in (9), the return on savings is given by

$$
r^{S}=f^{\prime}(k)-\delta=\frac{z}{q_{t}}+\frac{\dot{q_{t}}}{q_{t}}
$$

where $\dot{q}_{t} \geq 0$ in steady state depends on the presence of land price bubbles, which in turn depends on the specification of the utility from wealth. The natural rate of interest $r^{N}$ is derived from (14) with $\dot{c}_{t}=0$ as

$$
r^{N}=\rho-\frac{v^{\prime}(a)}{u^{\prime}(f(k)-\delta k+z)},
$$

where I use the goods market clearing condition (18) with $\dot{k}_{t}=0$ and $L=1$ to substitute for consumption under full employment as a function of the capital stock, i.e.

$$
c=f(k)-\delta k+z
$$

Note that consumption is maximized when the capital stock is at the Golden Rule level $\tilde{k}$, which is defined by $f^{\prime}(\tilde{k})=\delta$.

The real rate $r^{S}$ in (19) determines the actual return on assets and hence the saving incentives for households, while the natural rate $r^{N}$ in (20) describes the real return on savings that is necessary to achieve full employment. Hence, full employment requires $r^{S}=r^{N}$. An persistent oversupply of savings occurs for $r^{S}>r^{N}$ in steady state as the incentives to save are too high. This depresses aggregate demand and prevents full employment from materializing.

In the following, I analyze the feasibility of full employment and the role of land for different assumptions on the preference for wealth. I start with the neoclassical model without land as a benchmark. Most of the derivations and proofs are relegated to the appendix. 


\subsection{The Benchmark Model without Land}

Consider first the neoclassical model augmented for wealth preferences but without land. In equilibrium, household wealth is given by the capital stock as bonds are in zero net supply and $a=k$ in (20). ${ }^{16}$ The return on savings $r^{S}$ in (19) equals the net marginal product of capital without any further restrictions. Both $r^{N}$ and $r^{S}$ are continuous functions of the capital stock and illustrated in Figure 1 for the case of standard wealth preference (left panel) and a constant marginal utility of wealth $v^{\prime}(a)=\beta$ (right panel). Full employment requires $r^{S}=r^{N}$ or equivalently

$$
f^{\prime}(k)-\delta=\rho-\frac{v^{\prime}(k)}{u^{\prime}(f(k)-\delta k+z)} .
$$

Let $\bar{k}$ and $\bar{r}$ denote the steady state values of the capital stock and the real interest rate. The following proposition shows that the full employment steady state is always realized in this economy irrespective of the nature of the preference for wealth.

Proposition 1 The steady state under full employment, characterized by (22), always exists irrespective of the lower bound on the marginal utility of wealth. The steady state is unique under mild restrictions on preferences or model parameters. The dynamic system exhibits saddle-point stability around this steady state.

The proof is in Appendix A. I assume that the steady state is unique, which holds under mild restrictions as discussed in Kurz (1968) and Bose (1971). Graphically, uniqueness requires that the slope of $r^{N}$ exceeds the slope of $r^{S}$ at each intersection.

Full employment is sustainable even with insatiable wealth preferences because physical capital is both a store of value and a producible asset whose replacement affects aggregate demand. Suppose there was an excess supply of savings, i.e. $r^{N}<r^{S}$. As no other assets are available to absorb the excess savings, these have to be invested in bonds and physical capital. As a consequence, the capital stock increases and the net marginal product of capital declines as does the return on savings $r^{S}$. The depreciation rate constitutes a lower bound this return, i.e. $r^{S}>-\delta$.

In addition, the higher capital stock affects the natural rate via two channels. As households become wealthier, they prefer lower savings and higher consumption. The natural rate increases via this wealth channel as $v^{\prime}(a)$ declines. Higher values of the capital stock also affect the supply of goods. Increase in $k$ increase the net supply if $k$ is below the Golden Rule level $\tilde{k}$, which lowers the natural rate. The opposite holds if $k$ is above the Golden Rule, since more and more output is used for the replacement of the depreciating capital stock.

\footnotetext{
${ }^{16}$ Note that I assume that households receive the income $z$ despite the exclusion of land. In this case, $z$ should be interpreted as a lump-sum transfer. Hence, the expression for consumption in (21) continues to hold and there are no further changes to the natural rate in (20).
} 
Figure 1: The Steady State of the Benchmark Model
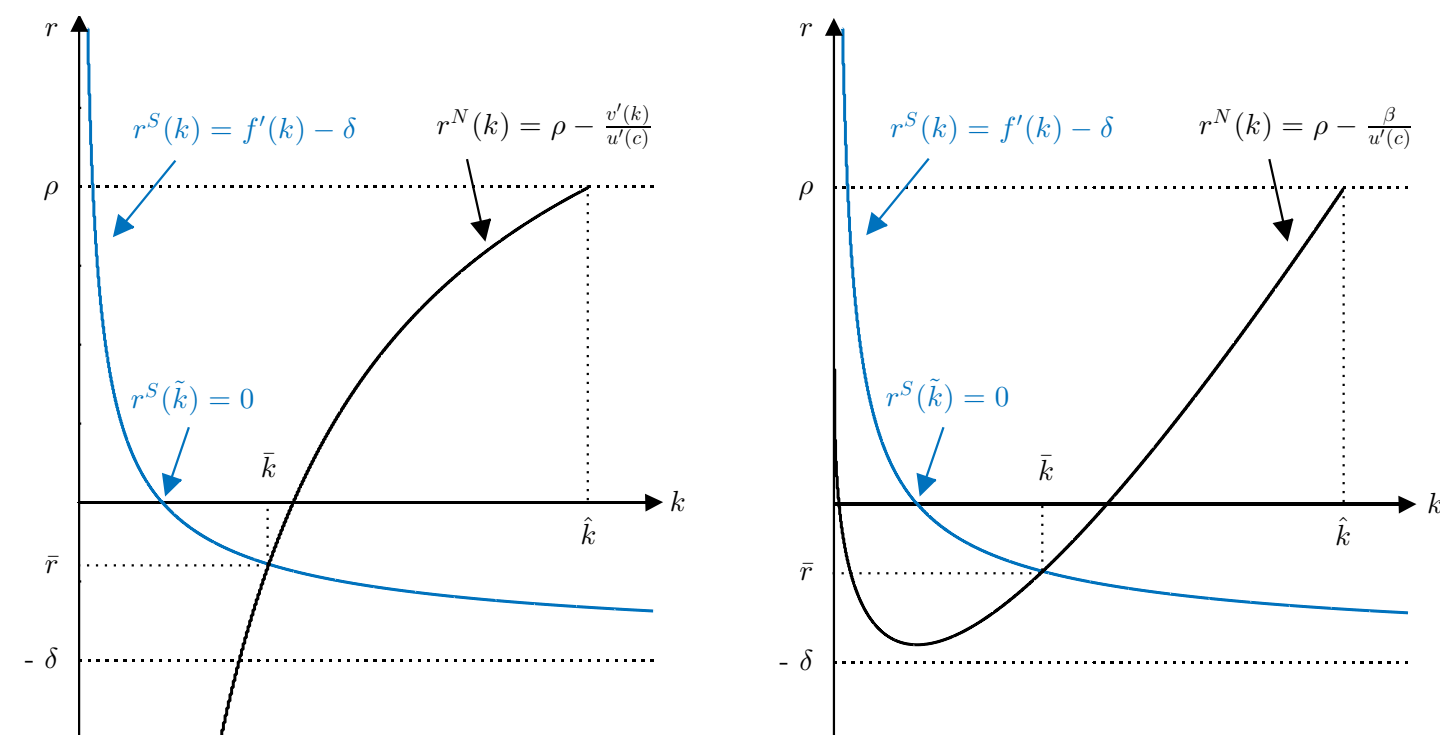

Note: This figure shows the natural interest rate $r^{N}$ and the real return on savings $r^{S}$ as a function of the capital stock $k$. The left graph shows the case of a declining marginal utility of wealth, i.e. $v^{\prime \prime}(a)<0$. The right graph shows the case of a constant marginal utility, i.e. $v^{\prime}(a)=\beta$.

For $k<\tilde{k}$, the net effect depends on the relative strength of these channels and the natural rate might increase (left panel) or decrease (right panel) for higher $k$. For $k>\tilde{k}$, the natural rate increases because of both wealth and income effects. Eventually, output is fully used up for investment and the natural rate approaches the time preference rate $\rho$ (at $\hat{k}$ in Figure 1). With a constant marginal utility of wealth, the wealth channel ceases to operate and increases in wealth no longer stimulate consumption. In contrast, the income channel continues to operate and the natural rate increases with the capital stock once it exceeds the Golden Rule level.

Taken together, any excess supply of savings is invested into physical capital and bonds. The associated increase in the capital stock reduces the return on savings and eventually increases the natural interest rate. Market clearing (22) is always feasible at full employment, even for a constant marginal utility of wealth. The steady state real rate satisfies $\bar{r} \in(-\delta, \rho)$, which can be negative for sufficiently strong wealth preferences. Then overaccumulation of capital above the Golden Rule level occurs.

Secular stagnation results from the existence of a non-producible store of value that affects the incentives for savings without, however, affecting full employment consumption. ${ }^{17}$ Money is an example of such an asset in a monetary economy, while land is an example of such an asset in a real economy.

\footnotetext{
${ }^{17}$ This is also the reason why the possibility of storage or the existence of non-depreciable capital does not allow for deviations from full employment. In this case, the lack of demand would be substituted by investment demand and $\dot{K}_{t}>0$ in steady state, which is sustainable if wealth preferences are insatiable.
} 


\subsection{The Neoclassical Model with Land}

Consider first the immediate effect of introducing land, which pays a fixed rent $z$ to its owner, into the neoclassical model. The existence of land prevents the real rate of interest from becoming negative in steady state as summarized in the following proposition.

Proposition 2 The steady state real interest rate in the presence of land cannot become negative, i.e. $r>0$, as a consequence of the No-Arbitrage condition (5) and the possibility of free disposal.

The intuition is as follows (see Appendix B for the proof). The land price cannot become negative due to free disposal, which also excludes the possibility of a declining price in steady state. As land yields a positive rent to its owner, the rental yield on land remains strictly positive and constitutes a real return which households can earn on their savings. The No-Arbitrage condition then implies that the returns on other assets cannot become negative as well. This result does not depend on the exogenous income component $z$, but holds as long as there is positive income or utility associated with ownership of the asset in steady state. ${ }^{18}$

It follows that the actual return on savings $r^{S}$ in (19) and hence the net marginal product of capital have to be strictly positive in an economy with land. Thus, the steady state capital stock will always be strictly below the Golden Rule level $\tilde{k}$ and I obtain the same result as Homburg (1991): The existence of a non-producible productive asset rules out dynamic inefficiency as well as the possibility of Golden Rule growth. Any excess savings can be invested in land at a positive rate of return. This result does not depend on the specification of the wealth preference.

In a purely fundamental steady state with $\dot{q}_{t}=0$, households earn the rental yield on land and the land value $q$ adjusts to equalize this yield to the net marginal product of capital. In a bubbly steady state with $\dot{q}_{t}>0$, the rental yield asymptotically approaches zero and the return on land is purely driven by the capital gain.

In addition, private wealth no longer coincides with the capital stock as households can invest in land. The land value then affects the natural interest rate $r_{t}^{N}$ via the wealth preference as $v(a)=v(k+q)$. As households are more wealthy, their desire for savings is reduced compared to the benchmark model and the natural rate increases for a given value of the capital stock.

Both the feasibility of full employment and the possibility of rational bubbles in the land price depend on the nature of the wealth preference.

\footnotetext{
${ }^{18}$ Alternatively, land can be modeled as a factor input in the production function (6) similar to capital, as in Homburg $(1991,2014)$. Then, $z$ is the rental price of land and equals the marginal product of land, which is strictly positive. Similarly, the real interest rate cannot become negative in the presence of housing that yields a positive user cost in terms of utility as in Illing et al. (2017) or in the presence of positive dividends from stock ownership as in Zhou (2013).
} 


\subsection{The Steady State with Standard Wealth Preferences}

Consider first the case of standard wealth preferences. The land price is constant in steady state and bubbles do not occur as summarized in the following proposition.

Proposition 3 With $\beta=0$, there cannot be an ever-growing or ever-decreasing land price. Therefore, we must have $\dot{q}_{t}=0$ in steady state. Moreover, the land price is purely fundamental and bubbles cannot exist, i.e. $q_{t}=q_{t}^{F}$ and $q_{t}^{B}=0$.

An ever-declining land price is not possible as the land price would eventually become negative as shown in the proof of Proposition 2 in the appendix. In contrast, an ever-growing land price implies that the land value becomes infinitely high and so does household wealth. With $\beta=0$, the marginal utility of wealth decreases to $v^{\prime}(a)=0$ and the natural rate converges to the time preference rate $\rho$ as can be seen in (20). The return on land eventually consists purely of the capital gain in (2), which also approaches $\rho$. As a consequence, the growth rate of both the land price and household wealth converges to $\rho$ as the capital stock is constant. However, this violates the transversality condition (15). Therefore, we must have $\dot{q}_{t}=0$ in steady state. It directly follows that there cannot be a bubble in equilibrium. Any bubble has to grow with the real interest rate as is clear from (4). This rate is strictly positive in steady state by Proposition (2). This implies $\dot{q}_{t}^{B}>0$, which is not possible. ${ }^{19}$

With $\dot{q}_{t}=0$, the return on land is given by the rental yield in (2). The land price adjusts such that this return equals the net marginal product of capital. Full employment requires

$$
f^{\prime}(k)-\delta=\rho-\frac{v^{\prime}\left(k+\frac{z}{f^{\prime}(k)-\delta}\right)}{u^{\prime}(f(k)-\delta k+z)}>0 .
$$

This is the equivalent to condition (22) in the benchmark model. The return on savings is restricted to be positive due to the availability of land as a store of value.

Both, $r^{N}$ and $r^{S}$ are continuous functions of $k$ and illustrated in Figure 2. Let $k_{N C}^{*}$ and $r_{N C}^{*}$ denote the steady state values of the capital stock and the real rate. The following proposition shows that full employment is always feasible in this economy.

Proposition 4 The steady state under full employment, characterized by (23), always exists if $\beta=0$. This steady state is unique under mild restrictions on preferences or model parameters. It is characterized by a lower capital stock and a higher real rate than in the benchmark model without land. In addition, the model exhibits saddle-point stability around this steady state.

\footnotetext{
${ }^{19}$ This result depends on the assumption of no depreciation in the value of land. I do not consider the possibility of depreciation in the rent $z$ as the focus is on the nature of the wealth preferences. For the general case with depreciation, see Michau et al. (2017).
} 
Figure 2: The Steady State of the Neoclassical Model with Land for $\beta=0$
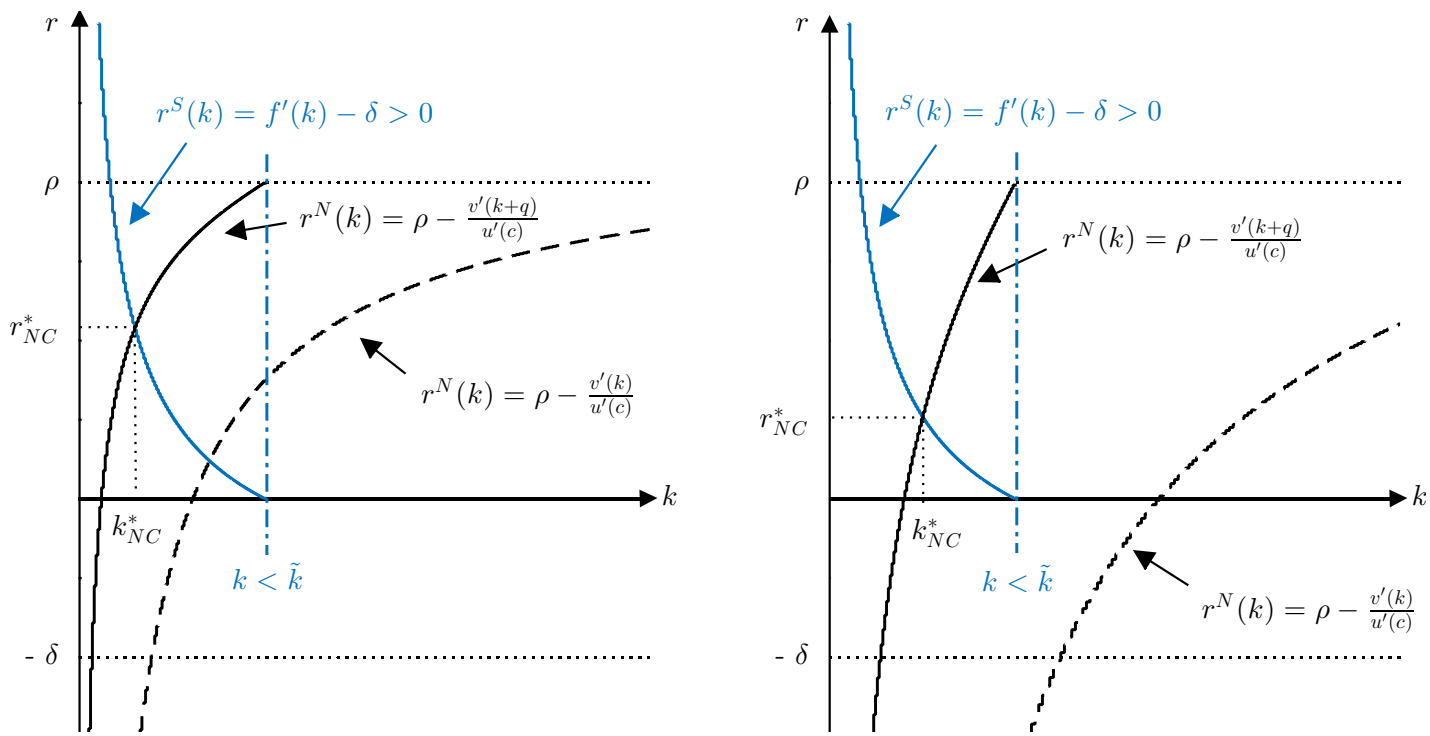

Note: This figure shows the natural rate $r^{N}$ for the model with land (solid line) and the benchmark model (dotted line) as well as the return on savings $r^{S}$ as a function of the capital stock $k$. The left graph shows the case of a positive real interest rate $\bar{r}>0$ in the benchmark model, whereas the right graph shows the case of a negative real interest rate $\bar{r}<0$ in the benchmark model. The return on savings is strictly positive as explained in Proposition 2, which is illustrated by the vertical line at $\tilde{k}$.

The proof is in Appendix C. As before, I assume uniqueness of the steady state.

For a given value of $k$, the return on savings $r^{S}$ is unaffected by the introduction of land, but restricted to be positive, which is represented by the vertical line at $\tilde{k}$. In contrast, household wealth is higher in the presence of land, which reduces the desire for savings and increases the natural rate $r^{N}$. Hence, the $r^{N}$ curve shifts upwards in Figure 2, which results in a lower capital stock and a higher real rate. Hence, $k_{N C}^{*}<\bar{k}$ and $r_{N C}^{*}>\bar{r}$. This holds for both a positive (left panel) and a negative (right panel) real rate $\bar{r}$ in the benchmark model.

The existence of land establishes a zero lower bound on the real return on savings as households can always invest in land at a positive return. Excess savings that could only be invested in physical capital in the benchmark model are channeled into land investment. Therefore, overaccumulation of capital cannot occur despite the preference for wealth.

In addition, the value of land also affects the natural rate. As the capital stock increases, the fundamental value of land increases and so does household wealth. As households become wealthier, their desire for savings declines and the natural rate increases. In fact, the land price becomes infinitely high when $k$ approaches $\tilde{k}$ and the natural rate $r^{N}$ approaches $\rho$, while the return on savings converges to zero. It follows that there always exists a capital stock $k_{N C}^{*}<\tilde{k}$ for which the return on savings matches the natural rate at full employment. This real rate is strictly positive at $r_{N C}^{*} \in(0, \rho)$. 


\subsection{The Steady State with Insatiable Wealth Preferences}

With $\beta>0$, a negative real interest rate is still ruled out by Proposition 2. However, the insatiability of wealth preferences gives rise to a continuum of land price paths that are compatible with equilibrium, including paths with exploding land price bubbles.

Proposition 5 With insatiable wealth preferences, there is a continuum of equilibrium paths for the land price. These include a constant steady state land price $\dot{q}_{t}=0$ as well as steady states with exploding land prices $\dot{q}_{t}>0$.

Similar to before, we cannot have a steady state with a declining land price as $q_{t} \geq 0$. In case of $\dot{q}_{t}=0$, the land price is simply given by its fundamental value, namely the capitalized value of rents $z$. This is the only solution if $\beta=0$. An ever-increasing land price in steady state implies that household wealth expands indefinitely. However, the marginal utility of wealth now converges to the lower bound $\beta>0$. As a consequence, the real interest rate remains strictly below the time preference rate as is clear from $(20)$ with $v^{\prime}(a)=\beta$. Then the return on land is purely given by the capital gains component in (19) as the rental yield becomes infinitely small. Therefore, the growth rates of the land price and household wealth are below the time preference rate $\rho$. The transversality condition (15) is not violated despite the expansion of the land value. Intuitively, this is because the strong preference for wealth prevents households from expanding their desired consumption spending in response to an increase in wealth. Hence, the resource constraint of the economy is not violated as wealth is accumulated without expanding consumption. Households prefer to keep their land investments rather than selling it to realize parts of the increase in value. ${ }^{20}$

This implies that rational bubbles are sustainable, which is in stark contrast to the case of $\beta=0$. For any initial bubble value $q_{0}^{B}>0$, the bubble component of the land price will grow with the real return on savings as can be seen from (4). As this rate is strictly positive by Proposition 2, the bubble component will grow in steady state, thereby expanding household wealth. Eventually, the lower bound on the wealth preference is obtained and we have $v^{\prime}(a)=\beta$.

In the steady state of the model with land and insatiable wealth preferences, full employment cannot always be realized. In that case, there exist a range of values $L<1$ that are compatible with market clearing but the resulting secular stagnation steady state is not well-defined. This result is summarized in the following proposition.

\footnotetext{
${ }^{20}$ Similar conclusions are obtained by Ono (1994), Kamihigashi (2008) and Zhou (2013, 2015) about the dynamics of equity prices based on non-standard behavior of wealth preferences. The first two papers also assume a lower bound on the marginal utility of wealth, while the last one restricts the behavior of the marginal rate of substitution between wealth and consumption. In all cases, the real rate does not converge to the time preference rate as wealth expands and the transversality condition is not violated.
} 
Proposition 6 In the model with land and $\beta>0$, the economy operates at full employment in steady state if

$$
\beta<\rho u^{\prime}(c(\tilde{k}))
$$

where $\tilde{k}$ is the Golden Rule capital stock. The steady state then has the same stability properties as in the case of standard wealth preferences. In contrast, the economy fails to operate at full employment and there exist a range of values $L<1$ compatible with market clearing if condition (24) is violated and if the rent from land ownership $z$ is sufficiently low, specifically if

$$
\rho u^{\prime}(z)>\beta \geq \rho u^{\prime}(c(\tilde{k}))
$$

This result holds for both a constant land price and in the presence of land price bubbles. However, the secular stagnation steady state with $L<1$ is not well-defined.

I give an intuitive outline here (see Appendix D for the proof). Consider first the case of land price bubbles. In a bubbly steady state, we have $\dot{q}_{t}^{B}>0$ in (4) as $r^{S}>0$ by Proposition 2. Both the land price and real wealth expand indefinitely and $v^{\prime}(a)=\beta$ in the asymptotic steady state. Hence, the natural rate in (20) no longer depends on household wealth and attains a minimum at the Golden Rule capital stock $\tilde{k}$. In contrast, the return on savings is unaffected compared to the previous case. Both returns are illustrated in Figure $3 .{ }^{21}$ Full employment requires

$$
f^{\prime}(k)-\delta=\rho-\frac{\beta}{u^{\prime}(f(k)-\delta k+z)}>0
$$

This is the equivalent to conditions (22) and (23) before. Full employment is not feasible if the preference for wealth is sufficiently strong. With $\beta=0$, increases in the land price reduce the desire of households for savings and increase the natural rate into positive territory. In contrast, with insatiable wealth preferences, increases in the land price at some point cease to stimulate consumption. The desire for saving remains sufficiently strong. Investment demand does not expand as excess savings are invested in land instead of capital. As a consequence, an oversupply of saving occurs and the goods market cannot clear at full employment.

The same argument holds for the fundamental steady state with a constant land price. In this case, households wealth is finite and we have $v^{\prime \prime}(a)<0$. Full employment requires

$$
f^{\prime}(k)-\delta=\rho-\frac{v^{\prime}\left(k+\frac{z}{f^{\prime}(k)-\delta}\right)}{u^{\prime}(f(k)-\delta k+z)}>0,
$$

\footnotetext{
${ }^{21}$ Note that the bubbly steady state with insatiable wealth preferences is identical to the benchmark model with a constant marginal utility of wealth that is depicted in the right panel of Figure 1, except for the additional restriction of $r^{S}>0$. In the model without land, we have instead $\bar{r} \in(-\delta, \rho)$.
} 
Figure 3: The Steady State of the Neoclassical Model with Land for $\beta>0$
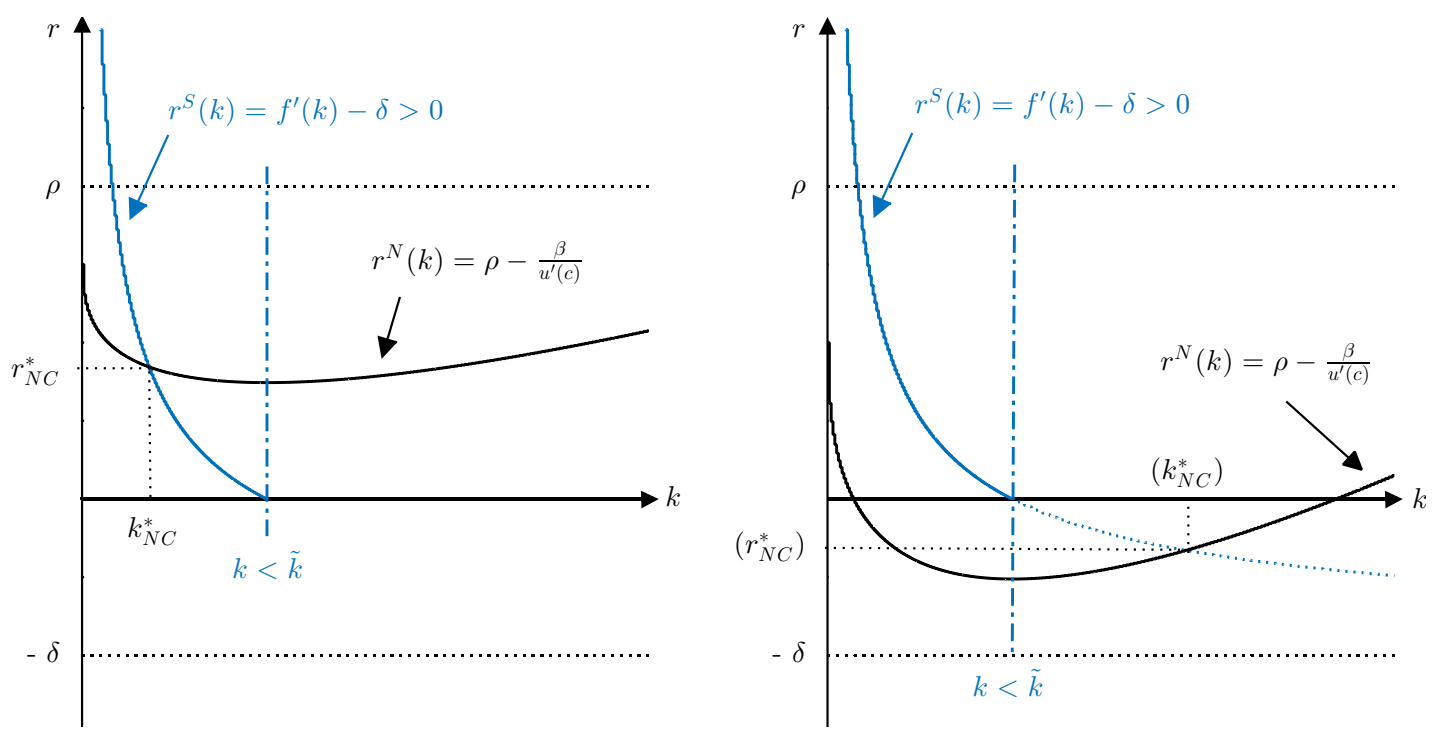

Note: This figure shows the natural interest rate $r^{N}$ for the model with land and $v^{\prime}(a)=\beta$ in the bubbly steady state as well as the return on savings $r^{S}$ as a function of the capital stock $k$. In the left graph, condition (24) holds and $r^{S}>0$ is not violated under full employment since $\beta$ is sufficiently low. In the right graph, condition (24) is violated. Market clearing at full employment would require a negative interest rate, which is precluded by the possibility of land investment.

which is identical to (23) and the dynamics and stability properties of the model economy are the same as in the case of $\beta=0$. Yet, the realization of full employment depends on the lower bound $\beta$. Specifically, the marginal utility of wealth approaches its lower bound once the steady state capital stock approaches $\tilde{k}$ since the value of land becomes infinitely high. Full employment at a positive real rate can only occur if the natural rate at $\tilde{k}$ exceeds the actual return on savings, which is zero at the Golden Rule level. Existence of the full employment steady state then depends on the same condition as in the bubbly steady state since the value of the natural rate at $\tilde{k}$ is identical in both cases.

Hence, condition (24) determines the feasibility of full employment in the steady state with $\beta>0$. In Figure 3, this condition holds in the left panel, while it is violated in the right panel.

Consider a concrete example to illustrate the factors that determine the feasibility of full employment. Assume the standard production function $f(k)=k^{\alpha}$ and a constant intertemporal elasticity of substitution $\sigma>0$ with $u^{\prime}(c)=c^{-\sigma}$. The Golden Rule level of the capital stock is given by $f^{\prime}(\tilde{k})=\delta$ and the Golden Rule level of consumption satisfies $\tilde{c}=f(\tilde{k})-\delta \tilde{k}+z$. Full employment is no longer feasible if condition (24) is violated or alternatively if condition (25) holds. In this example, full employment is not feasible if

$$
\beta \geq \rho\left[(1-\alpha)\left(\frac{\alpha}{\delta}\right)^{\frac{\alpha}{1-\alpha}}+z\right]^{-\sigma} .
$$


Intuitively, factors that lower the desire for savings and increase the natural rate make full employment easier to sustain, while factors that reduce the natural rate make it more difficult.

Household preferences affect the feasibility of full employment. Specifically, a lower time preference rate $\rho$, a more concave utility function $u(c)$ and a stronger preference for wealth $\beta$ increase the desire of households for savings and reduce the natural rate.

In addition, a higher depreciation rate $\delta$ implies that more output is used for investment to replace the depreciated capital stock, which lowers consumption under full employment for a given $k$. This increases the natural interest rate. In contrast, a higher capital intensity of production $\alpha$ increases the supply of goods available for consumption, which lowers the natural rate and makes full employment harder to sustain. ${ }^{22}$

Finally, higher rental income $z$ from land ownership increases consumption under full employment as well as desired savings. The natural rate decreases.

To summarize the analysis so far: Full employment is always feasible in a purely neoclassical economy with land and standard wealth preferences. In contrast, full employment cannot always be sustained despite the existence of land if wealth preferences are insatiable. In fact, it is the very existence of land that rules out the full employment steady state by preventing the real return on savings from becoming negative.

In a monetary economy, the inflation rate also creates a lower bound on the real return on savings due to the zero lower bound on the nominal rate. Yet, secular stagnation can occur in the monetary economy with standard wealth preferences as shown by Michaillat and Saez (2014) and Michau (2017), while it is not possible in the economy with land unless wealth preferences are insatiable. The reason is that money does not affect the utility from wealth in these models as it is not considered net wealth. The real money stock then does not affect the natural rate.

In the neoclassical economy with land, it is not the preference for wealth itself that prevents full employment in steady state but its insatiable nature. ${ }^{23}$ It results in a desire for savings that is too strong to clear markets at full employment. The oversupply of savings then causes a shortfall of the labor supply. In fact, there are multiple levels of the labor supply that are consistent with market clearing. Specifically, any $L<1$ that fulfills condition (25) in Proposition 6 defines a secular stagnation steady state. Secular stagnation is then not a monetary, but a real phenomenon. The steady state is however indeterminate in the absence of real wage rigidities. Therefore, I introduce money and downward nominal wage rigidity to determine the steady state.

\footnotetext{
${ }^{22}$ Note that higher depreciation or a lower capital intensity also lower the net marginal product of capital and shift the $r^{S}$ curve. However, it is the return on savings at the Golden Rule level that determines the feasibility of full employment. This return is always zero.

${ }^{23}$ Note that the insatiability of wealth preferences in the benchmark model is consistent with full employment as there is no non-producible productive store of value.
} 


\section{A Monetary Economy with Land}

I introduce money via a money-in-the-utility framework following Sidrauski (1967), where the central bank controls the nominal money supply. In addition, nominal rigidities limit the downward adjustment of wages and prevent deflationary wage-price spirals.

\subsection{Monetary Policy, Wage Setting Frictions and Inflation}

Money serves as a means of savings for households, in addition to bonds, capital and land, and it is a unit of account for the price level. Money does not pay interest, but provides households with a convenience yield due to its liquidity and transaction value.

The central bank directly controls the nominal money supply $M_{t}^{S}$, while the nominal interest rate $i_{t}$ is endogenously determined in the money market. Let $P_{t}$ denote the price level of the output good and $m_{t}^{s} \equiv M_{t}^{S} / P_{t}$ the real money supply. Similarly let $m_{t}^{d}$ denote the real money demand of households. In equilibrium, the money market clears such that

$$
\frac{M_{t}^{S}}{P_{t}} \equiv m_{t}^{s}=m_{t}^{d}=m_{t}
$$

Let $\mu$ denote the growth rate of the nominal money supply. The real money supply then evolves as

$$
\dot{m}_{t}=\left(\mu-\pi_{t}\right) m_{t}
$$

where $\pi_{t}$ denotes the rate of inflation. In the monetary economy, bonds pay a nominal interest rate $i_{t}$, which is related to the real rate of return via the Fisher Equation as

$$
r_{t}=i_{t}-\pi_{t}
$$

As land and capital are real assets, their returns are unaffected by the introduction of money and the No-Arbitrage condition (5) continues to hold, with the return on bonds given by (30).

In addition, the firm problem is unaffected and the rental price of capital and the real wage are still determined by the marginal products of capital and labor in (7) and (8). The latter implies that the real wage is constant in steady state. Therefore, the inflation rate always equals the change in the nominal wage $W_{t}$ in steady state.

I assume downward nominal wage stickiness. Specifically, I follow Schmitt-Grohé and Uribe (2016, 2017) and postulate that nominal wages cannot fall by more than an exogenous rate $\gamma$, i.e.

$$
\frac{\dot{W}_{t}}{W_{t}} \geq-\gamma
$$


A value of $\gamma=0$ implies that nominal wages cannot fall at all, whereas $\gamma=1$ allows for perfectly flexible wages. ${ }^{24}$ Equation (31) is only binding in case of stagnation, hence the complementary slackness constraint

$$
\left(1-L_{t}\right)\left(\frac{\dot{W}_{t}}{W_{t}}+\gamma\right)=0 .
$$

Under full employment we have $L_{t}=1$ and (31) is not binding. The inflation rate is determined by the money supply growth rate $\mu$ as can be seen from (29) with $\dot{m}_{t}=0$. The central bank can perfectly control the inflation rate and money is fully neutral. The price level adjusts to clear the money market in (28). It is then the dynamics of the price level that determine nominal wage dynamics.

In contrast, we have $L_{t}<1$ under stagnation and (31) is binding. Nominal wages decline at a constant rate $\gamma$. The dynamics of the nominal wage determine the inflation rate $\pi$ as the real wage is given by (8). Taken together, the rate of inflation is determined as

$$
\pi_{t}=\frac{\dot{P}_{t}}{P_{t}}=\left\{\begin{array}{l}
\mu \text { if } L_{t}=1 \\
-\gamma-\frac{\dot{w}_{t}}{w_{t}} \text { if } L_{t}<1
\end{array}\right.
$$

I assume $\mu \geq 0>-\gamma$. Hence, the economy is deflationary under stagnation, but not under full employment. Under stagnation, inflation is related to changes in the real wage, which are determined by changes in the capital-labor ratio as $\dot{w}_{t}=-f^{\prime \prime}\left(k_{t}\right) k_{t} \dot{k}_{t}$ from (8). In steady state, the inflation rate is constant as $\dot{k}_{t}=0$ and hence $\dot{w}_{t}=0 .{ }^{25}$

\subsection{Households and the Natural Rate of Interest (Revisited)}

Money is a store of value for households. Total real wealth $a_{t}$ is now given by the household's real bond holdings $b_{t} \equiv B_{t} / P_{t}$, with $b_{t}=0$ in equilibrium, the value of real capital, the value of land and the real money holdings as

$$
a_{t}=b_{t}+k_{t} L_{t}+q_{t} H_{t}+m_{t}
$$

\footnotetext{
${ }^{24}$ The same assumption is adopted by Hanson and Phan (2017) and Biswas et al. (2017). Similar relationship are used among others in Ono and Ishida (2014), Eggertsson, Mehrotra, and Robbins (2017), Caballero and Farhi (2018) or Michau (2017). They are derived from nominal frictions in the wage setting process like fairness concerns of workers or the prevalence of a wage norm or a reference wage. For a review of the empirical evidence on wage stickiness, see section 8 in Schmitt-Grohé and Uribe (2016).

${ }^{25}$ The asymmetry in the inflation process based on nominal wage stickiness is a common feature of models of secular stagnation and can be found among others in Ono and Ishida (2014), Michau (2017) or Illing et al. (2017). In this setting, the inflation rate in the secular stagnation steady state is determined by structural factors, which affect the degree of wage stickiness $\gamma$, and hence unaffected by the labor supply gap. In contrast, the inflation rate depends on the steady state output gap in Ono and Ishida (2014), Illing et al. (2017) and Schmitt-Grohé and Uribe (2017).
} 
and, using the No-Arbitrage condition (5) for the returns on capital and land, real wealth evolves as

$$
\dot{a}_{t}=r_{t} a_{t}-i_{t} m_{t}-c_{t}+w_{t} L_{t}+\tilde{z}_{t}
$$

where I assume that all seignorage income $\tilde{z}_{t} \equiv \mu m_{t}$ is redistributed to households in a lump-sum fashion. Holding money creates opportunity losses equal to the nominal interest rate $i_{t}$.

I follow the money-in-the-utility literature and I assume that real money balances generate utility $\omega\left(m_{t}\right)$ to households as they are a liquid means of payment. This function fulfills the standard assumptions of $\omega^{\prime}(m)>0, \omega^{\prime \prime}(m)<0, \lim _{m \rightarrow 0} \omega^{\prime}(m)=\infty$ and $\lim _{m \rightarrow \infty} \omega^{\prime}(m)=0$. The lifetime utility of households is given by

$$
U_{0}=\int_{0}^{\infty}\left[u\left(c_{t}\right)+\omega\left(m_{t}\right)+v\left(\tilde{a}_{t}\right)\right] e^{-\rho t} d t
$$

which is the standard Sidrauski (1967) model except for the wealth preference $v\left(\tilde{a}_{t}\right)$. Households maximize (36) subject to (35), which gives the optimality condition for the intertemporal allocation of consumption and optimal money demand as

$$
\begin{gathered}
\eta_{c} \frac{\dot{c}_{t}}{c_{t}}=r_{t}-\rho+\frac{v^{\prime}\left(\tilde{a}_{t}\right)}{u^{\prime}\left(c_{t}\right)}, \text { where } \eta_{c} \equiv-\frac{u^{\prime \prime}\left(c_{t}\right) c_{t}}{u^{\prime}\left(c_{t}\right)}, \\
\frac{\omega^{\prime}\left(m_{t}\right)}{u^{\prime}\left(c_{t}\right)}=i_{t} .
\end{gathered}
$$

In addition, the transversality condition (15) continues to apply to real household wealth.

The Euler Equation in (37) is unaffected by the introduction of money, except for the difference in the wealth composition in (34). It is up for debate if the real money stock constitutes net wealth of households and generates utility via the wealth preference. Both views can be found in the literature. Ono $(1994,2015)$ makes the case for including money in the utility from wealth. Then $v\left(\tilde{a}_{t}\right)=v\left(a_{t}\right)$ as before and the natural rate increases for a given $k$ compared to the neoclassical model. As households feel wealthier, their desire to save declines. In contrast, Michaillat and Saez (2014) and Michau (2017) argue that only wealth generated by real assets affects the utility from wealth. ${ }^{26}$ Then $v\left(\tilde{a}_{t}\right)=v\left(a_{t}-m_{t}^{S}\right)$ and the real money stock does not affect the wealth preference. The natural rate is the same as in the purely neoclassical economy. From the perspective of the individual household, the assumption $v\left(\tilde{a}_{t}\right)=v\left(a_{t}\right)$ seems more natural. However, I will analyze the implications of both views.

\footnotetext{
${ }^{26}$ Michaillat and Saez (2014) assume that the central bank issues money to buy household bonds. The wealth created by money is therefore equal to the bond liability and net wealth equals the stock of physical capital. Similarly, Michau (2017) argues that both government debt and money do not constitute net wealth of households as both need to be redeemed eventually.
} 
The nominal rate $i_{t}$ determines optimal money demand in (38). Households equate the liquidity premium, which is the marginal rate of substitution between money and consumption, to the nominal interest rate on bonds. In fact, (38) represents a No-Arbitrage relation between money and bonds and establishes a zero lower bound on the nominal interest rate. The wealth preference itself does not affect money demand directly.

The real return on money $r_{t}^{M}$ affects the return on savings $r_{t}^{S}$ as money is a store of value for households. The nominal return on money consists of the liquidity premium in (38). Using the Fisher Equation (30) and inflation in (32), the real return on money satisfies

$$
r_{t}^{M}=\frac{\omega^{\prime}\left(m_{t}\right)}{u^{\prime}\left(c_{t}\right)}-\pi_{t}=\left\{\begin{array}{l}
\frac{\omega^{\prime}\left(m_{t}\right)}{u^{\prime}\left(c_{t}\right)}-\mu \text { if } L_{t}=1 \\
\frac{\omega^{\prime}\left(m_{t}\right)}{u^{\prime}\left(c_{t}\right)}+\gamma+\frac{\dot{w}_{t}}{w_{t}} \text { if } L_{t}<1
\end{array}\right.
$$

Asset market clearing requires the equalization of the real returns on money, bonds, land and capital. The No-Arbitrage condition (5) is extended to include money as

$$
r_{t}=r_{t}^{M}=r_{t}^{K}=r_{t}^{L}\left(=r_{t}^{B}\right)
$$

where $r_{t}^{K}, r_{t}^{L}, r_{t}^{B}$ and $r_{t}^{M}$ are given by (9), (2), (4) and (39). This constitutes the real return on savings $r_{t}^{S}$, which households receive irrespective of the asset in which they invest.

\section{Analysis of the Monetary Economy}

The equilibrium of the economy is characterized by the Euler Equation (38), the return on land (2), the return on capital (9), the return on money (39), the goods market clearing condition (18), the money supply process in (29) and the No-Arbitrage condition (40), together with the transversality condition (15), where household wealth is given by (34), for a given initial value of capital $K_{0}>0$. Under full employment $L_{t}=1$ and $K_{t}=k_{t}$. Under stagnation $L_{t}<1$ and $K_{0}>0$ is given while $k_{t}>K_{t}$. In steady state, it holds that $\dot{c}_{t}=0$ and $\dot{k}_{t}=0$, which implies $\dot{K}_{t}=0$ and $\dot{L}_{t}=0$. The properties of $\dot{q}_{t}$ and $\dot{m}_{t}$ depend on $v(\tilde{a})$.

The actual return on savings $r^{S}$ in steady state is determined by the No-Arbitrage condition (40) that requires the equalization of real returns across assets as

$$
r^{S}=\left\{\begin{array}{l}
\frac{\omega^{\prime}\left(M^{S} / P\right)}{u^{\prime}(f(k)-\delta k+z)}-\mu \text { if } L_{t}=1 \\
\gamma \text { if } L_{t}<1
\end{array}\right\}=f^{\prime}(k)-\delta=\frac{z}{q_{t}}+\frac{\dot{q}_{t}}{q_{t}}>0
$$


where I used money market equilibrium (28) and goods market equilibrium (18) to substitute for optimal money demand and consumption. Note that Proposition 2 continues to hold, which is why $r^{S}$ is required to be strictly positive.

Under full employment, the real money stock increases in the capital stock of the economy. An increase in $k$ lowers the net marginal product of capital and increases consumption as $k<\tilde{k}$. This makes holding money more attractive and increases money demand of households. For a given money supply $M^{S}$, the price level $P$ declines to clear the money market. As a consequence, the real money stock increases and the nominal interest rate is lowered until $r^{M}=r^{K}$. As the nominal interest rate is strictly positive, the money growth rate $\mu$ - or equivalently the inflation target of the central bank - represents a lower bound on the return on savings when the economy operates at full employment. This lower bound is what prevents the return on savings from adjusting to the natural rate in other models of secular stagnation. In the model with land, this lower bound is only binding in an economy that is deflationary under full employment, i.e. if $\mu<0$. For positive inflation rates, it is always the non-negativity restriction imposed by the existence of land that represents the minimum return on household savings.

In a secular stagnation steady state, the economy is deflationary and nominal wages and prices decline with rate $\gamma$. As a consequence, the real money supply expands indefinitely since $\mu+\gamma>0$. In this asymptotic steady state, money demand of households becomes satiated and the nominal interest rate converges to zero. The return on savings is then determined by the rate of deflation and the capital stock adjusts accordingly.

The existence of a steady state requires the equalization of the return on savings $r^{S}$ defined in (41) with the natural rate of interest $r^{N}$ in (37) with $\dot{c}_{t}=0$, taking into account the wealth composition. The full employment steady state exists if

$$
\frac{\omega^{\prime}\left(M^{S} / P\right)}{u^{\prime}(f(k)-\delta k+z)}-\mu=f^{\prime}(k)-\delta=\rho-\frac{v^{\prime}(\tilde{a})}{u^{\prime}(f(k)-\delta k+z)}>0
$$

where I use the goods market clearing condition under full employment (18) to substitute for consumption in (37) and where wealth is defined by the wealth composition (34) with $b_{t}=0$, $L_{t}=1$ and $H_{t}=1$. For $v(\tilde{a})=v(a)$, the natural rate increases for a given $k$ compared to the previous section as money is part of net wealth in $v(a)$. In contrast, for $v(\tilde{a})=v\left(a-m^{S}\right)$, the real rate is determined in the real economy and unaffected by the introduction of money. Once the real rate is determined, and strictly positive for full employment to be feasible, households adjust their desired money holdings such that $r^{M}=r^{S}$ from (40) and the price level adjusts to clear the money market in (28). Money is fully neutral as an exogenous increase in the money supply will simply result in a proportional increase in the price level. 
In addition, for a secular stagnation steady state to exist, it has to hold that

$$
\gamma=f^{\prime}(k)-\delta=\rho-\frac{v^{\prime}(\tilde{a})}{u^{\prime}([f(k)-\delta k] L+z)}>0
$$

where I use goods market clearing condition (18) with $L<1$ to substitute for consumption in (37). Under stagnation, the inflation rate is determined by the binding wage rigidity and the return on money equals the rate of deflation as the nominal rate becomes asymptotically zero. The capital-labor ratio is determined by the No-Arbitrage condition between the net marginal product of capital and the return on money. The expansion of the money supply reduces the marginal utility of wealth to its lower bound in the asymptotic steady state for $v(\tilde{a})=v(a)$.

The feasibility of full employment and stagnation depend on the nature of the utility from wealth. As before, I distinguish again between standard and insatiable wealth preferences.

\subsection{The Case of Standard Wealth Preferences}

The steady state with standard wealth preferences is characterized by a constant land price as Proposition 3 continues to hold. Hence, the land price is given by the capitalized value of rents and bubbles do not exist. The same argument applies to the real money stock. Under full employment, we have $\pi_{t}=\mu$ from (33) and the real money supply is constant from (29). In a secular stagnation steady state, the real money supply expands indefinitely since $\mu+\gamma>0$. The expansion of the money supply increases the natural rate to $\rho$, which eventually violates the transversality condition for $v(\tilde{a})=v(a) \cdot{ }^{27}$

Full employment is always feasible in a neoclassical economy with land and $\beta=0$ as shown in Proposition 4. The respective condition for the monetary economy is as follows.

Proposition 7 In the monetary model with $\beta=0$, the full employment steady state in (42) is the unique equilibrium if the real money stock affects the utility from wealth, i.e. if $v(\tilde{a})=v(a)$. The secular stagnation steady state in (43) cannot exist for $v(\tilde{a})=v(a)$.

For the case of $v(\tilde{a})=v\left(a-m^{S}\right)$, the full employment steady state is not feasible if

$$
\mu<-r_{N C}^{*}<0
$$

where $r_{N C}^{*}>0$ denotes the steady state real rate in the neoclassical model with land.

The full employment steady state is unique under mild restrictions and the dynamic system exhibits saddle-point stability around this steady state.

\footnotetext{
${ }^{27}$ The expansion of the real money supply under stagnation does not affect the real interest rate for $v(\tilde{a})=$ $v\left(a-m^{S}\right)$. Then, money can expand without violating the transversality condition if $\mu+\gamma<\rho$.
} 
Figure 4: The Steady State of the Monetary Model with Land for $\beta=0$
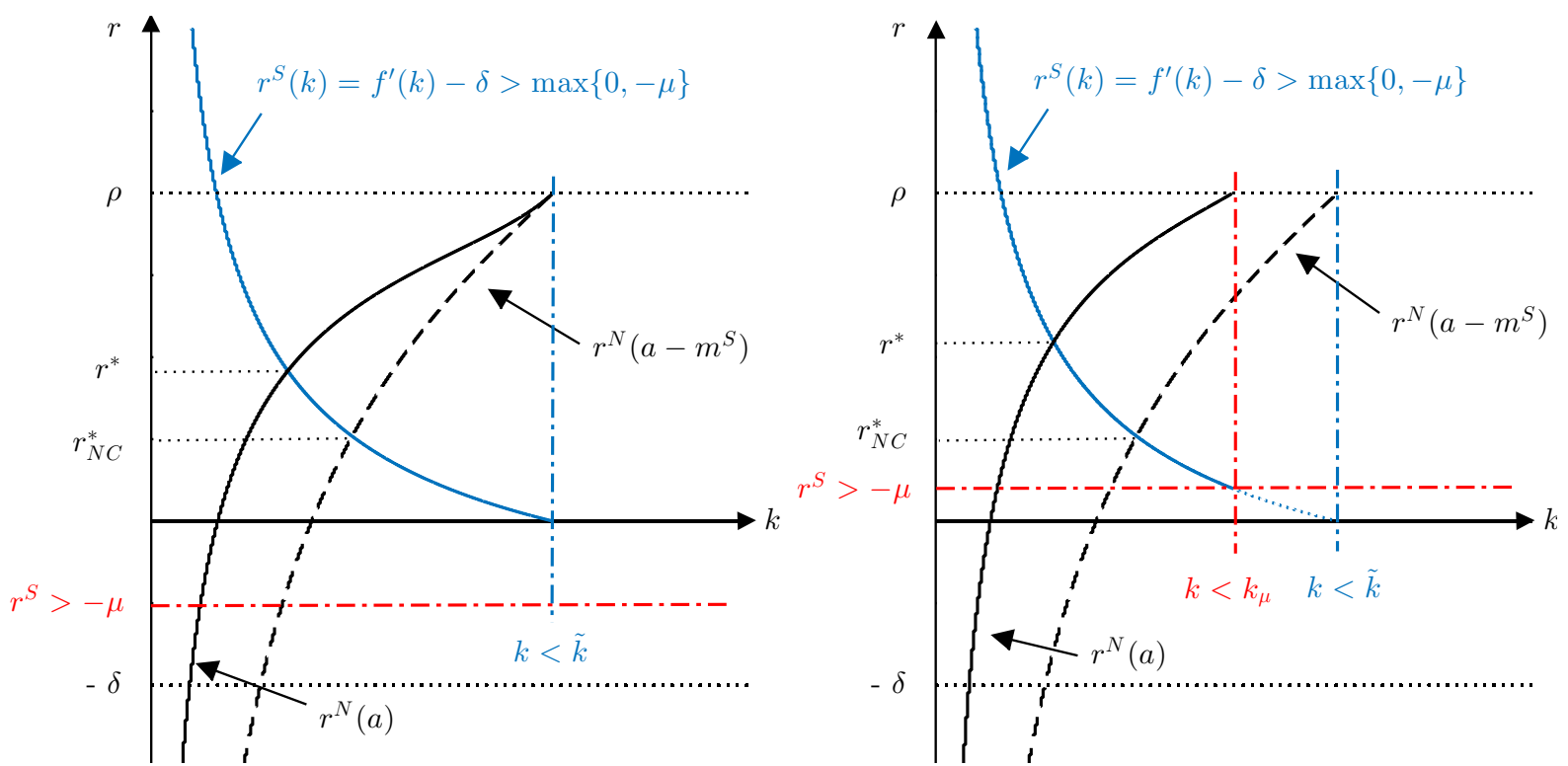

Note: This figure shows the natural rate $r^{N}$ for the monetary economy (solid line) and the neoclassical model with land (dotted line) as well as the return on savings $r^{S}$ as a function of the capital stock $k$. The dotted line also represents the natural rate for $v(\tilde{a})=v\left(a-m^{S}\right)$. The left graph assumes $\mu \geq 0$, whereas the right graph shows $0>\mu>-\gamma$. $\tilde{k}$ is the Golden Rule capital stock, $k_{\mu}$ is defined by $f^{\prime}\left(k_{\mu}\right)=\delta-\mu$.

The proof is relegated to Appendix E. The intuition is illustrated in Figure 4, which shows the natural rate for the neoclassical economy with land (dotted line) and the monetary economy with $v(\tilde{a})=v(a)$ (solid line). The dotted line also represents the natural rate for the case of $v(\tilde{a})=v\left(a-m^{S}\right)$. The natural rate in the monetary economy exceeds the natural rate in the neoclassical economy due to the higher wealth level for a given $k$ if $v(\tilde{a})=v(a)$. The return on savings is unaffected, but potentially restricted by the introduction of money. The restrictions $r^{S}>0$ from land $(k<\tilde{k})$ and $r^{S}>-\mu$ from money $\left(k<k_{\mu}\right)$ are also illustrated.

Consider first the case of an inflationary economy with $\mu \geq 0$, which is shown in the left panel of Figure 4. It is the existence of land that provides a lower bound on the real interest rate as the nominal interest rate exceeds the real rate. Full employment is always feasible as land price increases stimulate the natural rate towards $\rho$ once the capital stock approaches the Golden Rule level. This is the same mechanism as in the neoclassical model with $\beta=0$.

In a deflationary economy with $\mu<0$ (right panel), the existence of money creates a lower bound on the return on savings. Yet, increases in the real money stock have a similar effect as land for $v(\tilde{a})=v(a)$. A lower real rate increases money demand to lower the nominal rate for a given inflation rate. This requires an increase in the real money stock to clear the money market. The corresponding increase in monetary wealth stimulates the natural rate towards $\rho$ (for $k=k_{\mu}$ ) and full employment is always feasible. 
However, this channel only works when real money balances affect the natural rate in steady state, which is illustrated by the curve $r^{N}(a)$. If households do not derive utility from monetary wealth, the natural rate is independent of the real money stock, which is curve $r^{N}\left(a-m^{S}\right)$. Then, the steady state real interest rate is unaffected by the introduction of money and given by $r_{N C}^{*}$, which is the same rate as in the neoclassical model with land of section 3 . This rate satisfies $r_{N C}^{*} \in(0, \rho)$. If the economy is sufficiently deflationary, the real return on savings can be persistently above the natural rate. This requires $\mu<-r_{N C}^{*}$. Then full employment is not feasible despite the existence of land as the incentives for savings by holding cash are too high. ${ }^{28}$

As long as the economy under full employment is characterized by price stability or positive trend inflation, the full employment equilibrium is always feasible with standard wealth preferences once land is available as a means of investment. In fact, it is the only feasible equilibrium of the model economy when money affects the utility from wealth. Then, secular stagnation cannot occur as either the increase in land prices for $\mu \geq 0$ or the expansion of the real money supply for $\rho>-\mu>0$ absorbs any excess savings.

If wealth preferences are instead given by $v(\tilde{a})=v\left(a-m^{s}\right)$, the possibility of stagnation is not ruled out by the presence of land. Then the full employment and a secular stagnation steady state can coexist and it is unclear which one is realized. In a monetary economy without land, this secular stagnation steady state occurs as the unique outcome if the central bank follows a low inflation target as in Michaillat and Saez (2014) and Michau (2017). Secular stagnation then becomes a policy choice and full employment can be restored by choosing a sufficiently high inflation target. In contrast, full employment is always feasible in an economy with land and standard wealth preferences unless in the implausible scenario of the central bank following a strong deflation target. The secular stagnation steady state can, however, exist as the unique equilibrium of the economy when wealth preferences are insatiable.

\subsection{The Case of Insatiable Wealth Preferences}

With a lower bound on the marginal utility of wealth, rational bubbles with $\dot{q}_{t}>0$ are possible in a stationary steady state with $\dot{c}_{t}=\dot{k}_{t}=0$ as shown in Proposition 5. The same argument implies that an infinite expansion of the money supply, i.e. $\dot{m}_{t}>0$, is consistent with the transversality condition in a secular stagnation steady state if the rate of expansion is below the time preference rate $\rho$. For simplicity, I will assume in the following analysis that there are no bubbles, i.e. $q_{t}^{B}=0$. The steady state with bubbles is identical to the case of $v^{\prime}(\tilde{a})=\beta$ due to an expanding real money stock for $v(\tilde{a})=v(a)$.

\footnotetext{
${ }^{28}$ Note that the existence of a full employment equilibrium always requires $\mu>-\rho$ since the natural rate cannot exceed the time preference rate $\rho$.
} 
The following proposition is the equivalent to Proposition 6 in the neoclassical economy.

Proposition 8 In the monetary economy with $\beta>0$, full employment is not feasible if

$$
\begin{array}{ll}
\beta>\rho u^{\prime}(c(\tilde{k})) & \text { for } \mu \geq 0, \\
\beta>(\rho+\mu) u^{\prime}\left(c\left(k_{\mu}\right)\right) & \text { for } \mu<0 \text { and } v(\tilde{a})=v(a), \\
\mu<-r_{N C}^{*} & \text { for } \mu<0 \text { and } v(\tilde{a})=v\left(a-m^{S}\right),
\end{array}
$$

where $\tilde{k}$ and $k_{\mu}$ are defined by $f^{\prime}(\tilde{k})=\delta$ and $f^{\prime}\left(k_{\mu}\right)=\delta-\mu$. In addition, there exists a secular stagnation steady state with $0<L<1$ if

$$
\begin{aligned}
& \frac{\beta}{u^{\prime}\left(f\left(k^{*}\right)-\delta k^{*}+z\right)}>\rho-\gamma>\frac{\beta}{u^{\prime}(z)} \quad \text { for } v(\tilde{a})=v(a), \\
& \frac{v^{\prime}\left(k^{*}+\frac{z}{\gamma}\right)}{u^{\prime}\left(f\left(k^{*}\right)-\delta k^{*}+z\right)}>\rho-\gamma>\frac{v^{\prime}\left(\frac{z}{\gamma}\right)}{u^{\prime}(z)} \quad \text { for } \mu<0 \text { and } v(\tilde{a})=v\left(a-m^{S}\right),
\end{aligned}
$$

where $k^{*}$ is given by $f^{\prime}\left(k^{*}\right)=\delta+\gamma$, if the money growth rate is small and if nominal wages are sticky, specifically

$$
\begin{gathered}
\mu<\rho-\gamma, \\
\gamma<\rho .
\end{gathered}
$$

The full employment and secular stagnation steady states are unique under mild restrictions and the dynamic systems satisfy saddle-point stability around these steady states.

Consider first the case of $\mu \geq 0$, for which (45) is identical to (24) in Proposition 6. The lower bound on the return on savings $r^{S}$ always results from the availability of land and money does not impose a constraint. The existence of land implies that the real return on savings cannot become negative and that the capital stock cannot exceed the Golden Rule level. Once it approaches $\tilde{k}$, the land price becomes infinitely high but fails to stimulate the natural interest rate as the lower bound $\beta$ is binding. Hence, if the natural rate at the Golden Rule capital stock is positive, full employment is feasible. This is illustrated in the left panel of Figure 5.

In contrast, if the natural rate is negative at the Golden Rule level, an oversupply of savings occurs at full employment. Land prevents the real return on saving from falling below zero, while increases in the land price cease to stimulate the natural rate. The oversupply of savings depresses demand, the realized labor supply drops below the potential labor supply and secular stagnation occurs. This is illustrated in the right panel. The drop in the labor supply shifts the natural rate upwards and restores goods market equilibrium at a positive real rate. 
Figure 5: The Steady State of the Monetary Model with Land for $\beta>0$
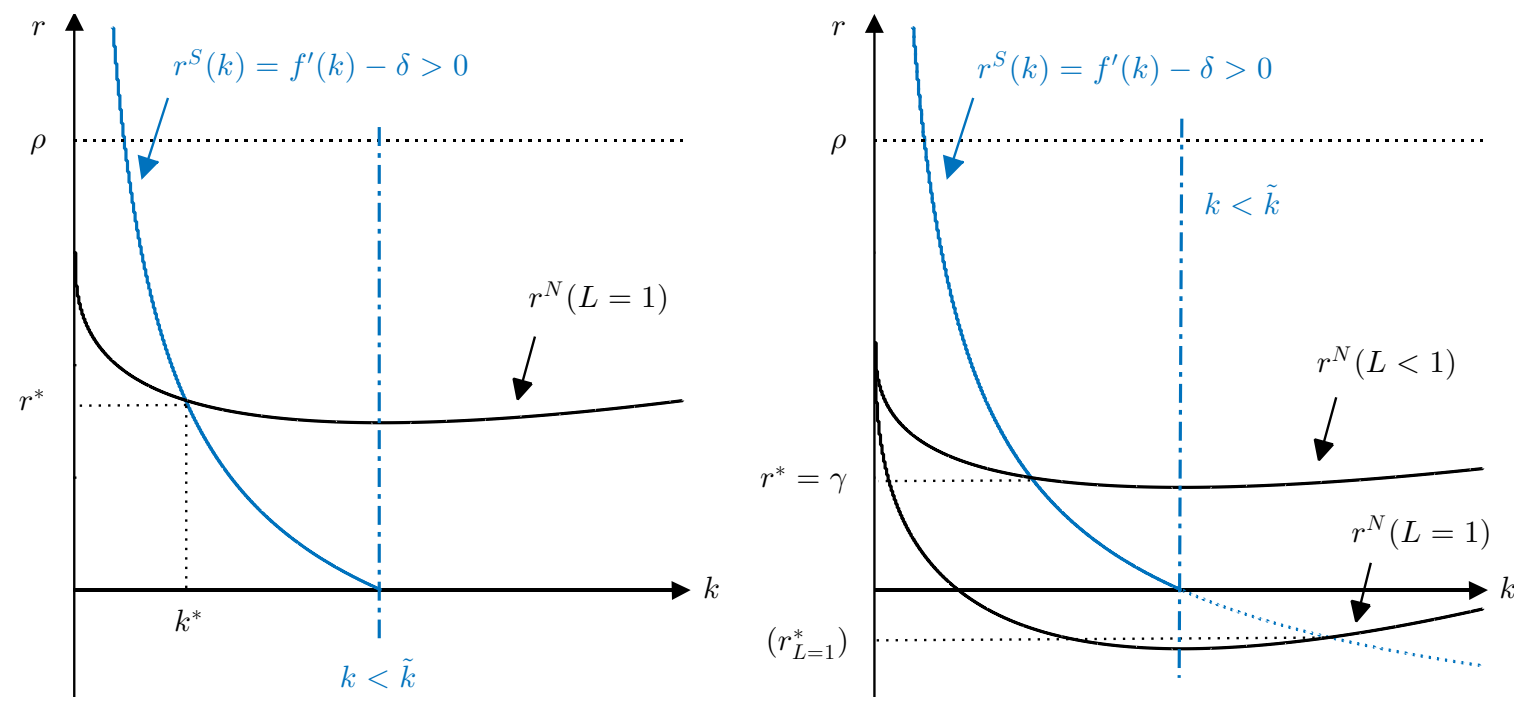

Note: This figure shows the natural rate $r^{N}$ for the monetary economy with $\beta>0$ as well as the return on savings $r^{S}$ as a function of the capital stock $k$ for $\mu \geq 0$ and $v^{\prime}(\tilde{a})=\beta$. The vertical lines represent the lower bound on the real rate imposed by the existence of land. Full employment condition (45) holds in the left graph, while it is violated in the right graph.

In a deflationary economy with $\mu<0$, the lower bound of the return on money exceeds the lower bound of the return on land. Therefore, money constrains the actual return on savings from falling below the rate of deflation. This implies that the capital stock under full employment cannot exceed $k_{\mu}<\tilde{k}$, with $f^{\prime}\left(k_{\mu}\right)=\delta-\mu$, at which both physical capital and money yield the same real return. Full employment is only feasible if the natural rate exceeds the return on savings at $k_{\mu}$. Otherwise, secular stagnation occurs. Note that condition (45) is independent of the lower bound $\beta$ for $v(\tilde{a})=v\left(a-m^{S}\right)$ and simply requires sufficiently weak wealth preferences. ${ }^{29}$

As the real money stock is part of household wealth, the transversality condition (15) is affected. In steady state, the growth rate of the real money supply $\mu-\pi$ cannot exceed the time preference rate $\rho$. Under full employment, the real money supply is constant and this always holds. In contrast, the growth rate under stagnation is given by $\mu-\gamma>0$. Hence, condition (47) requires $\rho>\mu-\gamma$.

Finally, condition (48) simply implies that the stagnation steady state is well-defined. If the rate of deflation under stagnation exceeds the time preference rate $\rho$, the return on savings is persistently higher than the natural interest rate, whose maximum is $\rho$. Hence, the good market does not clear for any level of the labor supply $L$ and a steady state therefore does not exist. Note that conditions (47) and (48) are identical for $\mu=0$.

\footnotetext{
${ }^{29}$ This condition is identical to condition (44) in Proposition 7. Under these assumptions, the secular stagnation steady state also exists for $\beta=0$. Yet, full employment is always possible in that case, while it is not feasible with $\beta>0$ although $v^{\prime \prime}(a)<0$ in steady state. Hence, it is the lower bound on the marginal utility of wealth that can result in secular stagnation as the unique feasible equilibrium.
} 
It is easy to see from Proposition 8 that secular stagnation is a monetary phenomenon only to the extent that the economy under full employment is deflationary. Then increases in the money growth rate $\mu$ can restore full employment. However, secular stagnation becomes a real phenomenon once $\mu \geq 0$. It is the result of the existence of land in combination with insatiable wealth preferences. Further increases in the money growth rate cannot restore full employment. Consider briefly the features of the full employment and the secular stagnation steady states.

The Full Employment Steady State: The economy behaves similar to the standard moneyin-the utility model. We have $L=1$ and $\pi=\mu$ from (33), which implies a constant real money supply. The land price can include a bubble as shown in Proposition (5), in which case $v^{\prime}(a)=\beta$. Without bubbles, the land price is finite. The capital stock is determined by $r^{S}=r^{N}$ in (42). From the capital stock, the real rate is derived as the net marginal product of capital. The land price is the rent $z$, capitalized with this rate, while consumption is determined from the market clearing condition. Given $c$ and $k$, households adjust their money demand such that $r^{M}=r^{S}$ from (40) and the price level adjusts to clear the money market in (28). Money is neutral as an increase in the money supply results in a proportional increase in the price level.

How does the land value affect the steady state? An exogenous increase in $z$ has two effects for a given $k$. On the one hand, the higher rent implies a higher fundamental land price, which increases household wealth and lowers the desire for savings. Hence, the natural rate increases. On the other hand, consumption under full employment increases, which reduces the natural rate. Hence, there is a wealth effect via higher land prices that causes the natural rate to increase and an income effect that lowers the natural rate. ${ }^{30}$ The wealth effect is stronger the higher the elasticity of the utility from wealth $\eta_{a} \equiv-\frac{v^{\prime \prime}(a) a}{v^{\prime}(a)}$. For high values of $\eta_{a}$, the increase in land prices causes a crowding out of investment and the capital stock declines. For sufficiently low values of $\eta_{a}$, the capital stock increases as the income effect dominates and there is crowding-in. ${ }^{31}$

The Secular Stagnation Steady State: The realized labor supply falls short of the potential labor supply, i.e. $L<1$, and the downward nominal wage constraint is binding. Hence, inflation is given by $\pi=-\gamma<0$ as can be seen in (33). The real money supply expands at rate $\mu+\gamma$, given that (47) holds. The liquidity demand of households is satiated and the nominal rate converges to $i_{t}=0$ from (38). Then, the real return on money in (39) is simply given by the

\footnotetext{
${ }^{30}$ In addition, the increase in consumption increases money demand for a given nominal rate. The resulting increase in the real money stock increases household wealth unless we have $v(\tilde{a})=v\left(a-m^{S}\right)$, which reinforces the wealth effect as it increases $\eta_{a}$.

${ }^{31}$ Note that the crowding out effect always dominates if the asset does not provided income directly. For instance, the value of land in Kocherlakota (2013) is derived from the utility it yields to households. Similarly, the real house price in Illing et al. (2017) depends on the convenience yield from housing.
} 
rate of deflation as $r^{M}=\gamma>0$ and, together with the No-Arbitrage condition (40), the steady state capital stock of the economy is uniquely determined as

$$
f^{\prime}\left(k^{*}\right)=\delta+\gamma>\delta
$$

which is above the Golden Rule level and hence consistent with the requirement of Proposition 2. In addition, the fundamental value of the land price equals the capitalized value of rents as

$$
q^{*}=\frac{z}{\gamma}>0
$$

although by Proposition 5 several bubbly steady states with $\dot{q}_{t}>0$ exist, where the bubble grows at rate $\gamma$ without violating the transversality condition as $\rho>\gamma$ by (48).

Market clearing requires the real return on savings to be consistent with the natural rate $r^{N}$. Since this is not feasible at full employment, households adjust their labor supply according to (43) such that

$$
\frac{\beta}{u^{\prime}\left(\left[f\left(k^{*}\right)-\delta k^{*}\right] L^{*}+z\right)}=\rho-\gamma,
$$

where $k^{*}$ is defined in (49). Note that we have $v^{\prime}(a)=\beta$ as $\dot{m}_{t}>0$ in the asymptotic steady state with $v(\tilde{a})=v(a)$ and $\dot{q}_{t}^{B}>0$ in the presence of bubbles. This condition does not depend on the money growth rate, but only on the degree of wage rigidity $\gamma$. The existence of the steady state requires wages to be sufficiently sticky, specifically $\rho>\gamma$. Condition (51) uniquely determines the labor supply gap under secular stagnation. In case of $v(\tilde{a})=v\left(a-m^{S}\right)$ and in the absence of bubbles, the respective condition is given by

$$
\frac{v^{\prime}\left(k^{*} L^{*}+q^{*}\right)}{u^{\prime}\left(\left[f\left(k^{*}\right)-\delta k^{*}\right] L^{*}+z\right)}=\rho-\gamma,
$$

where $v^{\prime \prime}(a)<0$ and $q^{*}$ is defined in (50). How do changes in the model parameters affect the secular stagnation steady state?

Higher wage flexibility worsens realized output under stagnation. An increase in $\gamma$ causes higher deflation and a higher return on savings $r^{S}$. The capital stock per worker decreases to provide for a higher return on capital in (49). This causes the natural rate $r^{N}$ to increase for a given labor input. The net effect is an excess supply of savings, which worsens the labor supply gap. The effect that increasing wage flexibility is detrimental under stagnation is common in models of stagnation and can be found among others in Eggertsson and Krugman (2012), Eggertsson, Mehrotra, and Robbins (2017) and Michau (2017). ${ }^{32}$

\footnotetext{
${ }^{32}$ Similarly, an increase in the depreciation rate increases the capital stock per worker in (49). Yet, it also lowers the supply of goods available for consumption. It is unclear which effect dominates.
} 
In addition, a higher time preference rate $\rho$ implies a higher realized labor supply. As households are less patient, their desire for saving decreases and the natural rate increases. Since the capital-labor ratio is unchanged, this causes excess demand. Moreover, stronger preferences for wealth reduce the natural rate without affecting the steady state capital-labor ratio. Consequently, a higher value of $\beta$ causes the labor supply to decline.

A higher land rent $z$ causes the fundamental value of land to increase. In case of $v^{\prime \prime}(a)<0$, the net effect of the opposing income and wealth effects depends on the elasticities of $u(c)$ and $v(a)$. However, the wealth effect ceases to affect the natural rate if $v^{\prime}(a)=\beta$. Therefore, the income effect dominates. As aggregate supply increases, the natural rate is lowered, which requires a lower labor input in steady state. Hence, land price increases worsen stagnation, though via the indirect effect on aggregate supply. ${ }^{33}$

To summarize, it is the existence of land together with the insatiable nature of the utility from wealth that results in the secular stagnation steady state as the unique equilibrium given the conditions in Proposition 8. Stagnation becomes a real phenomenon for $\mu \geq 0$, which in contrast to other stagnation models does not rely on restrictive inflation targets of the monetary authority. It is the possibility of investment in land that prevents the central bank from restoring full employment. As a consequence, an increase in the inflation target, which is a popular policy recommendation of other secular stagnation models, ceases to be effective.

\subsection{Extension: A Risk Premium on Land}

So far, I have assumed that households require the same real returns on all assets in equilibrium. However, land typically is less liquid and subject to more macroeconomic risk as modeled by Caballero and Farhi (2018) or political risk than bonds and physical capital as argued by von Weizsäcker (2014). Therefore, I assume in this section that households require a real risk premium $\Delta>0$ for land investments above the risk-free return on bonds or physical capital. This risk premium is exogenous.

It follows that the required return on land is given by $r_{t}^{L}=r_{t}^{S}+\Delta$. This holds for both the fundamental land price and a land price bubble. Asset market clearing requires the risk-free rate on savings $r^{S}$ in steady state to satisfy the No-Arbitrage condition

$$
r^{S}=\frac{\dot{q}_{t}}{q_{t}}+\frac{z}{q_{t}}-\Delta=f^{\prime}(k)-\delta=\left\{\begin{array}{l}
\frac{\omega^{\prime}\left(M^{S} / P\right)}{u^{\prime}(f(k)-\delta k+z)}-\mu \text { if } L_{t}=1 \\
\gamma \text { if } L_{t}<1
\end{array}\right.
$$

\footnotetext{
${ }^{33}$ This conclusion is opposite to Kocherlakota (2013), who shows how land price declines worsen stagnation in an overlapping generations model. However, land yields utility rather than income in his setting so that changes in $z$ do not affect consumption directly.
} 
Using the same argument as in Proposition 2, the real return on land cannot become negative. The risk-premium then implies that the short-term real rate cannot fall below the premium. Specifically, it has to hold that

$$
r^{S}>-\Delta \text { and } k<k_{\Delta}
$$

where $k_{\Delta}$ is defined by $f^{\prime}\left(k_{\Delta}\right)=\delta-\Delta$. It follows that the risk-free rate can indeed become negative once a risk premium on land is included. The return on land can never be a restrictive factor for the return on savings if the risk premium is sufficiently high. Hence, I will assume $0<\Delta<\delta$. For simplicity, I abstract from the possibility of bubbles and assume a stationary land price in steady state, which is equal to the real rent $z$ capitalized at the required return from land $r^{S}+\Delta .^{34}$

The risk premium affects the feasibility of full employment with both standard wealth preferences and insatiable wealth preferences. Full employment requires the return on savings in (53) to match the natural rate of interest. Specifically, it requires

$$
f^{\prime}(k)-\delta=\rho-\frac{v^{\prime}(\tilde{a})}{u^{\prime}[f(k)-\delta k+z]}>\max \{-\mu,-\Delta\}
$$

where $v(\tilde{a})=v(a)$ includes the real money stock or is net of money for $v(\tilde{a})=v\left(a-m^{S}\right)$. The binding constraint on the return on savings results from the risk premium on land or the money growth rate, whichever is lower in absolute terms. Proposition 7 is modified as follows.

Proposition 9 In the monetary economy with $\beta=0$ and $\Delta>0$, the full employment steady state in (55) is the unique equilibrium if the real money stock affects the wealth preference, i.e. if $v(\tilde{a})=v(a)$. The secular stagnation steady state cannot exist for $v(\tilde{a})=v(a)$.

For the case of $v(\tilde{a})=v\left(a-m^{S}\right)$, the full employment steady state is not feasible if

$$
\mu<-r_{N C}^{*}(\Delta)<\Delta
$$

where $r_{N C}^{*}(\Delta) \in(-\Delta, \rho)$ denotes the steady state real interest rate in the neoclassical model with land and a risk premium $\Delta>0$. It holds that $r_{N C}^{\prime}(\Delta)<0$.

This steady state is unique under mild restrictions and the dynamic system exhibits saddlepoint stability similar to the case of $\Delta=0$ in Proposition $\%$.

The proof is equivalent to the case of $\Delta=0$ in Appendix E and graphically illustrated in Figure 6 , which shows the different returns in the presence of a risk premium on land.

\footnotetext{
${ }^{34}$ The risk premium affects the conditions for rational bubbles. Each bubble has to grow with $r^{S}+\Delta$ to be feasible. This is not possible with standard wealth preferences due to the transversality condition since $r \rightarrow \rho$. With $\beta>0$, rational bubbles are possible if $\Delta<\beta / u^{\prime}\left(c^{*}\right)$, where $c^{*}$ is consumption in steady state.
} 
Figure 6: The Steady State of the Model with Risk Premium for $\beta=0$
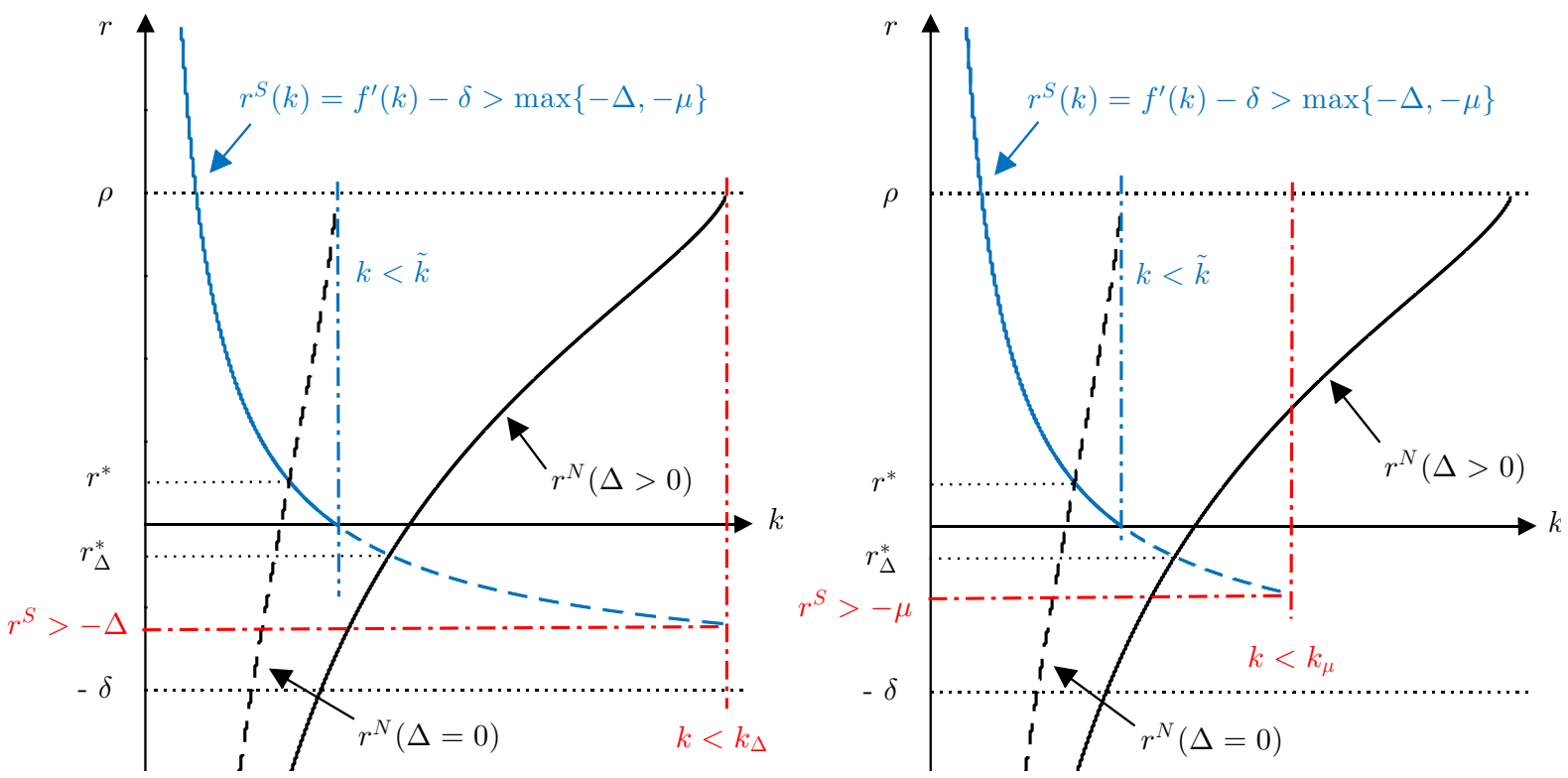

Note: This figure shows the natural rate $r^{N}$ for the model with (solid line) and without risk premium (dotted line) as well as the return on savings $r^{S}$ as a function of the capital stock $k$. The left graph assumes an increase in $\Delta$, whereas the right graph shows an increase in $\mu$. The restrictions $r>-\Delta$ and $r>-\mu$ are represented by the dotted vertical and horizontal lines. $k_{\Delta}$ and $k_{\mu}$ are defined by $f^{\prime}\left(k_{\Delta}\right)-\delta=-\Delta$ and $f^{\prime}\left(k_{\mu}\right)-\delta=-\mu$.

The introduction of the risk-premium lowers the real return $r_{N C}^{*}$ in the steady state of the neoclassical model with land. For a given $k$, a higher risk premium reduces the land price, which lowers household wealth. The marginal utility from wealth increases and the natural interest rate declines. As a consequence, the capital stock is reduced and so is the return on savings, which might become negative as well. This is illustrated in the left graph of Figure 6.

Full employment is feasible despite the negative interest rate if the real money stock is part of the wealth preference, i.e. $v(\tilde{a})=v(a)$, for the same reason as before. Whenever the real rate approaches its lower bound, the associated increases in the land price or the real money stock stimulate the natural rate into positive territory via the wealth preference. Hence, $r^{N}$ approaches $\rho$ whenever $k$ approaches $k_{\Delta}$ or $k_{\mu}$ in the left graph.

However, if the real money stock does not affect household wealth, the money growth rate can become a binding constraint on the real return on savings for $\Delta>\mu$. Hence, secular stagnation can occur as the result of an increase in the risk premium together with a strict inflation target. This is illustrated in the right graph of Figure 6 , where $\Delta$ increases while $\mu=0$. As the natural rate declines following the increase in the risk premium, a low money growth rate prevents the return on savings from falling sufficiently. Since the real money stock does not stimulate the natural rate via the wealth preference for $v(\tilde{a})=v\left(a-m^{S}\right)$, full employment cannot be realized if $\mu<-r_{N C}^{*}(\Delta>0)$, which is condition (56) in Proposition 9. 
In this case, full employment can be restored by both an increase in the money growth rate $\mu$ or a reduction in the risk premium on land $\Delta$. The first measure directly lowers the return on money and allows the real return on savings to match the lower natural rate. The second measure increases the land price and therefore stimulates the natural rate $r^{N}$. Hence, a higher money growth rate and a reduction in the risk premium can restore full employment with standard wealth preferences. Once $\Delta=0$, full employment is always feasible unless the economy is deflationary and $v(\tilde{a})=v\left(a-m^{S}\right)$.

Consider now the case of insatiable wealth preferences, which is described in Proposition 8 for $\Delta=0$. With a risk premium on land, the modified version is as follows.

Proposition 10 In the monetary economy with $\beta>0$ and a risk premium $\Delta>0$ on land investment, full employment is not feasible if

$$
\begin{array}{ll}
\beta>(\rho+\Delta) u^{\prime}\left(c\left(k_{\Delta}\right)\right) & \text { for } \mu \geq \Delta, \\
\beta>(\rho+\mu) u^{\prime}\left(c\left(k_{\mu}\right)\right) & \text { for } \Delta>\mu \text { and } v(\tilde{a})=v(a), \\
\mu<-r_{N C}^{*}(\Delta) & \text { for } \Delta>\mu \text { and } v(\tilde{a})=v\left(a-m^{S}\right),
\end{array}
$$

where $k_{\Delta}$ is given by $f^{\prime}\left(k_{\Delta}\right)=\delta-\Delta$ and $k_{\mu}$ by $f^{\prime}\left(k_{\mu}\right)=\delta-\mu$. In addition, there exists a secular stagnation steady state with $0<L<1$ if

$$
\begin{aligned}
& \frac{\beta}{u^{\prime}\left(f\left(k^{*}\right)-\delta k^{*}+z\right)}>\rho-\gamma>\frac{\beta}{u^{\prime}(z)} \quad \text { for } v(\tilde{a})=v(a), \\
& \frac{v^{\prime}\left(k^{*}+\frac{z}{\gamma+\Delta}\right)}{u^{\prime}\left(f\left(k^{*}\right)-\delta k^{*}+z\right)}>\rho-\gamma>\frac{v^{\prime}\left(\frac{z}{\gamma+\Delta}\right)}{u^{\prime}(z)} \quad \text { for } \Delta>\mu \text { and } v(\tilde{a})=v\left(a-m^{S}\right),
\end{aligned}
$$

where $k^{*}$ is given by $f^{\prime}\left(k^{*}\right)=\delta+\gamma$. Moreover, conditions (47) and (48) of Proposition 8 continue to apply. The full employment and secular stagnation steady states are unique under mild restrictions and the dynamic systems satisfy saddle-point stability.

The proof is equivalent to the case of $\Delta=0$ in Appendix $\mathrm{F}$ and graphically illustrated in Figure 7. Propositions 9 and 10 reduce to Propositions 7 and 8 for $\Delta=0$.

With a positive lower bound on the marginal utility from wealth, increases in the land price or the real money stock cease to stimulate the natural rate at some point, which remains permanently below the time preference rate and potentially below the return on savings. Then full employment is not feasible and stagnation occurs. For a sufficiently low risk premium, it is the return on land that constitutes a lower bound on the return on savings $r^{S}$, while the money growth rate provides the lower bound and stagnation is a monetary phenomenon for $\mu<\Delta$. 
Figure 7: The Steady State of the Model with Risk Premium for $\beta>0$
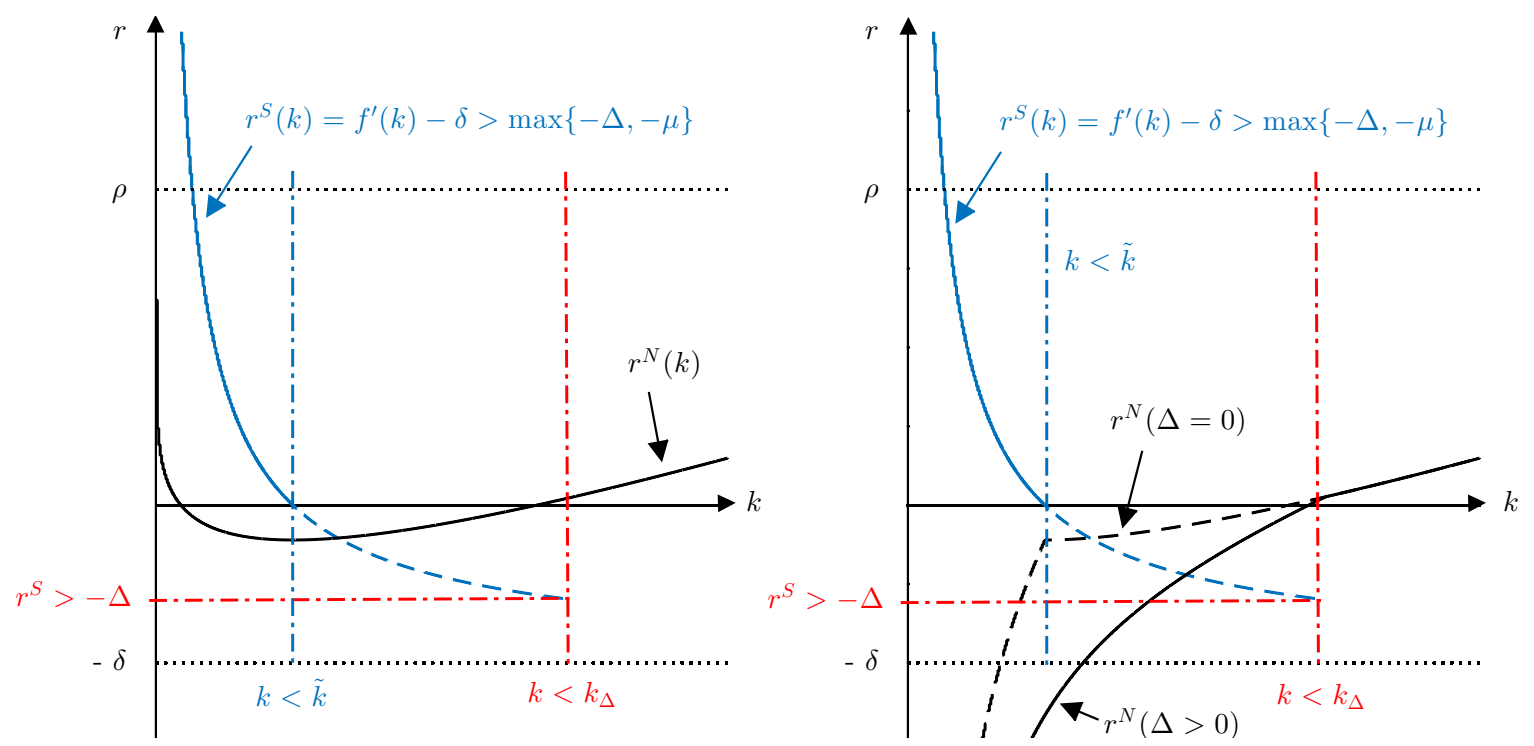

Note: This figure shows the natural rate $r^{N}$ as well as the return on savings $r^{S}$ as a function of the capital stock $k$. In the left graph, $v^{\prime}(a)=\beta$, while $v(\tilde{a})=v\left(a-m^{S}\right)$ is shown in the right graph. Both graphs assume an increase in $\Delta$. The vertical and horizontal lines represent the lower bounds on the real rate imposed by land.

If stagnation is a monetary phenomenon, increases in the money growth rate can restore full employment by lowering the return on money. This is the same effect as in the case of $\beta=0$ and $v(\tilde{a})=v\left(a-m^{S}\right)$. However, they cease to be effective for $\mu \geq \Delta$ as stagnation becomes a real phenomenon due to the existence of land. To see this, note that condition (57) is independent of the money growth rate for $\mu \geq \Delta$.

With insatiable wealth preferences, the effects of a reduction in the risk premium $\Delta$ are in stark contrast to the case of standard preferences, where lowering the risk premium helps to restore full employment, similarly to an increase in the inflation target. With insatiable wealth preferences, a reduction in the risk premium makes full employment actually harder to sustain and can result in secular stagnation.

A lower risk premium increases the minimum return on savings $r^{S}$. However, the associated increase in the land price ceases to stimulate the natural rate sufficiently to be compatible with full employment. With $v^{\prime}(a)=\beta$, the natural rate is unaffected by the risk premium, which is illustrated in the left panel of Figure 7. The steady state interest rate under full employment is negative, which is only sustainable if the inflation rate $\mu$ and the risk premium $\Delta$ are sufficiently high. Then, lowering the risk premium can make full employment unfeasible. The same effect holds with $v(\tilde{a})=v\left(a-m^{S}\right)$ and $v^{\prime \prime}(a)<0$, which is illustrated in the right graph. Although a lower risk premium stimulates the natural rate, the effect on the minimum return on savings always dominates and full employment is not feasible for a low risk premium under (57). 
The risk premium also affects the steady state properties. Under full employment, a reduction in the risk premium reduces the capital stock as it increases the natural rate of interest. As a consequence, consumption falls if the capital stock is below the Golden Rule level or expands if the capital stock is above the Golden Rule level.

In the secular stagnation steady state, the risk premium does not affect the capital stock per worker, which is determined by (49). ${ }^{35}$ In addition, consumption and output are unaffected for $v^{\prime}(a)=\beta$ as changes in wealth no longer affect the desire for savings. Then variations in the risk premium simply result in changes in asset prices that do not feed back into the real economy. It is only for the case of $v(\tilde{a})=v\left(a-m^{S}\right)$ that a lower risk premium increases the realized labor supply and hence consumption under stagnation. However, the reduction in the risk premium can at the same time prevent a return to full employment.

To summarize, the conclusions of the previous sections hold in the general setting with a positive risk premium. With standard wealth preferences, full employment is feasible if the risk premium on land is below the money growth rate or if the real money stock yields utility to households in steady state. If $v(\tilde{a})=v\left(a-m^{S}\right)$, full employment is not feasible if the risk premium is high, but can be restored by a higher money growth rate.

In contrast, secular stagnation occurs as the unique steady state of the model if wealth preferences are insatiable and the risk premium or the inflation rate is sufficiently low. Then an increase in the risk premium can actually restore full employment, while a higher money growth rate is only effective if money is the restrictive factor. Lowering the risk premium can potentially stimulate consumption under stagnation, but it also makes full employment less sustainable.

\section{Conclusion}

Many advanced economies struggle to maintain full employment despite historically low nominal interest rates. Unconventional monetary policies have narrowed interest rate spreads and contributed to higher prices of stocks, land and other assets, but failed to stimulate household consumption and investment demand sufficiently.

I have presented a theory of secular stagnation in a monetary economy with land that can rationalize these observations. Persistent stagnation can occur in steady state as a consequence of a permanent oversupply of savings. Households are not willing to consume at full employment because holding money or investing in land is more attractive. The return on these assets might be too high for full employment to be feasible.

\footnotetext{
${ }^{35}$ Note that the model can be extended to include a risk premium on the return on capital as well. Then equation (49) is affected by variations in the risk premium on capital. A higher spread decreases the capital stock under stagnation.
} 
In a monetary economy, the rate of inflation constrains the real return from savings and the feasibility of full employment effectively becomes a policy choice. In contrast, the availability of land implies that the real interest rate cannot fall below zero or the risk premium on land.

With standard wealth preferences, the introduction of land substantially weakens the case for secular stagnation as any excess savings are invested in land and the associated increase in the fundamental value of land stimulates household consumption via the wealth preference. Full employment is not feasible for a sufficiently low inflation rate, but only if monetary wealth does not affect the utility from wealth. Then, both an increase in the money growth rate or a reduction in the risk premium on land can restore full employment.

In contrast, the case for secular stagnation becomes stronger with insatiable wealth preferences. Then, increases in wealth at some point cease to stimulate consumption and secular stagnation occurs as the unique equilibrium. It is the very existence of land that accounts for the failure of the economy to operate at full employment since the possibility of land investment prevents the real return on savings from falling sufficiently.

Stagnation in an economy with land is therefore a real phenomenon and cannot always be cured by monetary policy. In particular, higher inflation targets cease to be effective in restoring full employment when spreads are low. In addition, policies to reduce spreads in financial markets might have unintended negative consequence and prevent full employment from being feasible if the risk premium on land becomes too low. Therefore, fiscal policy seems to be more appropriate, particularly with respect to tax policy as discussed in detail in Michau (2017). 


\section{A Proof of Proposition 1}

Let $\hat{k}$ be defined by $f(\hat{k})-\delta \hat{k}+z=0$ such that $c(\hat{k})=0$ in $(21)$. Define $\tilde{k}$ by $f^{\prime}(\tilde{k})=\delta$ as the Golden Rule level of the capital stock. Define $k^{+}$by $f^{\prime}\left(k^{+}\right)=\delta+\rho$, such that the net marginal product and the return on savings at $k^{+}$equal $\rho$. It holds that $k^{+}<\tilde{k}<\hat{k}$.

Full employment condition (22) defines the function $F(k)$ as the difference between the return on savings and the natural interest rate as

$$
F(k) \equiv f^{\prime}(k)-\delta-\rho+\frac{v^{\prime}(k)}{u^{\prime}(f(k)-\delta k+z)}
$$

Existence: The full employment steady state exists if there is $\bar{k}>0$ such that $F(\bar{k})=0$. $F(k)$ is a continuous function of $k$ in $(0, \hat{k})$. It holds that $F(k)>0$ for $k<k^{+}$. Also, $F\left(k^{+}\right)=$ $v^{\prime}(.) / u^{\prime}()>$.0 and $F(\hat{k})=f^{\prime}(\hat{k})-\delta-\rho=f^{\prime}(\hat{k})-f^{\prime}\left(k^{+}\right)<0$. It follows that there exists $\bar{k} \in\left(k^{+}, \hat{k}\right)$ with $F(\bar{k})=0$, irrespective of $\beta>0$ or $\beta=0$.

Uniqueness: Wealth preferences can result in multiple equilibria, see Kurz (1968) and Bose (1971). Uniqueness requires restrictions on the third moments of $v(a)$ and $u(c)$ as in Kurz (1968) or restrictions on the model parameters, particularly on $\rho$, as in Bose (1971). $F^{\prime}(\bar{k})<0$ for all $\bar{k}$ with $F(\bar{k})=0$ is a sufficient condition for uniqueness. ${ }^{36}$ Specifically,

$$
F^{\prime}(\bar{k})<0 \leftrightarrow\left[\rho+\delta-f^{\prime}(\bar{k})\right]\left[f^{\prime}(\bar{k})-\delta\right]<f^{\prime \prime}(\bar{k}) \frac{u^{\prime}(\bar{c})}{u^{\prime \prime}(\bar{c})}+\frac{v^{\prime \prime}(\bar{k})}{u^{\prime \prime}(\bar{c})}
$$

for all $\bar{k}$ with $F(\bar{k})=0$. This property has to hold locally at each $\bar{k}$. All terms on the RHS are weakly positive. Hence, uniqueness is guaranteed for $\rho=0$. The same holds for $\rho$ sufficiently close to zero, where sufficiently is dependent on the functional form of $u(c)$ and $f(k)$, particularly their third derivatives. This is also the conclusion of Kurz (1968).

Stability: The dynamic system is given by the differential equations for consumption in (14) and the capital stock in (18) for a given initial value $k_{0}>0$ :

$$
\begin{gathered}
\dot{c}_{t}=\frac{c_{t}}{\eta_{c}}\left[f^{\prime}\left(k_{t}\right)-\delta-\rho+\frac{v^{\prime}\left(k_{t}\right)}{u^{\prime}\left(c_{t}\right)}\right], \\
\dot{k}_{t}=f\left(k_{t}\right)-\delta k_{t}+z-c_{t},
\end{gathered}
$$

\footnotetext{
${ }^{36}$ Since $F(k)$ is the difference between the return on savings $r^{S}$ and the natural rate $r^{N}$, this condition requires the slope of the natural rate to exceed the slope of the return on savings at each intersection. Intuitively, the $r^{S}$ curve has to intercept the $r^{N}$ curve in Figure 1 from above. The same requirement guarantees uniqueness for all extensions of the benchmark model.
} 
where I used (9) to substitute for the real rate in (14). Log-linearization around the steady state via a first-order Taylor approximation gives

$$
\left(\begin{array}{l}
\dot{c}_{t} \\
\dot{k}_{t}
\end{array}\right)=\left(\begin{array}{cc}
\rho+\delta-f^{\prime}(\bar{k}) & -\frac{u^{\prime}(\bar{c})}{u^{\prime \prime}(\bar{c})}\left[f^{\prime \prime}(\bar{k})+\frac{v^{\prime \prime}(\bar{k})}{u^{\prime}(\bar{c})}\right] \\
-1 & f^{\prime}(\bar{k})-\delta
\end{array}\right)\left(\begin{array}{c}
c_{t}-\bar{c} \\
k_{t}-\bar{k}
\end{array}\right),
$$

where I use the definition of $\eta_{c}$ to simplify. The eigenvalues $\lambda$ of the system solve

$$
\begin{gathered}
\Lambda(\lambda)=\lambda^{2}-\rho \lambda+\left[\rho+\delta-f^{\prime}(\bar{k})\right]\left[f^{\prime}(\bar{k})-\delta\right]-\left[f^{\prime \prime}(\bar{k}) \frac{u^{\prime}(\bar{c})}{u^{\prime \prime}(\bar{c})}+\frac{v^{\prime \prime}(\bar{k})}{u^{\prime \prime}(\bar{c})}\right] \\
=\left(\phi_{1}-\lambda\right)\left(\phi_{2}-\lambda\right)=\lambda^{2}-\left(\phi_{1}+\phi_{2}\right) \lambda+\phi_{1} \phi_{2}=0,
\end{gathered}
$$

where I rewrite the equation in terms of its solutions $\lambda_{1}=\phi_{1}$ and $\lambda_{2}=\phi_{2}$. Matching terms implies

$$
\phi_{1} \phi_{2}=\left[\rho+\delta-f^{\prime}(\bar{k})\right]\left[f^{\prime}(\bar{k})-\delta\right]-\left[f^{\prime \prime}(\bar{k}) \frac{u^{\prime}(\bar{c})}{u^{\prime \prime}(\bar{c})}+\frac{v^{\prime \prime}(\bar{k})}{u^{\prime \prime}(\bar{c})}\right]<0,
$$

which follows from (A.2). Hence, there is one negative and one positive eigenvalue and the system is saddle-point stable around the steady state. Any $k_{0}>0$ uniquely determines $c_{0}\left(k_{0}\right)$ and the system converges to the steady state along the saddle-path. Saddle-point stability holds globally, which can be seen in the phase diagram of (A.3) and (A.4).

\section{B Proof of Proposition 2}

Start with the differential equation (2) for the land price, $\dot{q}_{t}=r q_{t}-z$. Let $r$ denote the real rate in steady state. Define the integrating factor $\xi_{s}=e^{-\int r d s}=e^{-r s}$ to modify (2) as

$$
\begin{gathered}
{\left[\dot{q}_{s} \dot{\xi}_{s}\right]=\dot{q}_{s} \xi_{s}-q_{s} \dot{\xi}_{s}=\left[\dot{q}_{s}-r q_{s}\right] \xi_{s}=-z \xi_{s}} \\
q_{t} \xi_{t}-A=-z \int_{0}^{t} \xi_{s} d s=-z \int_{0}^{t} e^{-r s} d s=-z\left[-\frac{1}{r} e^{-r t}+\frac{1}{r}\right] \\
q_{t}=\xi_{t}^{-1} A-\xi_{t}^{-1} z\left[-\frac{1}{r} e^{-r t}+\frac{1}{r}\right]=A e^{r t}-z e^{r t}\left[-\frac{1}{r} e^{-r t}+\frac{1}{r}\right]=\left[A-\frac{z}{r}\right] e^{r t}+\frac{z}{r}
\end{gathered}
$$

Let $q_{0}$ denote the steady state land price at $t=0$. Then, $q_{0}=A$ and the steady state price at time $t$ is given by:

$$
q_{t}=\left[q_{0}-\frac{z}{r}\right] e^{r t}+\frac{z}{r}
$$


Free disposal of land implies $q_{t} \geq 0$ for all $t$. From (B.1), $q_{t} \geq 0$ requires $r>0$ as $q_{t}$ approaches $z / r<0$ if $r<0$. For the special case of $r=0$, equation (B.1) becomes

$$
q_{t}=q_{0}-z t
$$

which for any $q_{0}>0$ eventually becomes negative. Hence $r=0$ is also not possible in steady state. We therefore must have $r>0 .{ }^{37}$ Equation (B.1) with $r>0$ rules out $\dot{q}_{t}<0$ in steady state. For any $q_{0}>0$, this eventually results in $q_{t}<0$, which is not possible.

\section{Proof of Proposition 4}

Define $k^{+}$by $f^{\prime}\left(k^{+}\right)=\delta+\rho, \tilde{k}$ as the Golden Rule level and $\hat{k}$ by $c(\hat{k})=0$ as in Appendix A with $k^{+}<\tilde{k}<\hat{k}$.

Full employment condition (23) defines the function $G(k)$ as the difference between the return on savings and the natural interest rate as

$$
G(k) \equiv f^{\prime}(k)-\delta-\rho+\frac{v^{\prime}\left(k+\frac{z}{f^{\prime}(k)-\delta}\right)}{u^{\prime}(f(k)-\delta k+z)} .
$$

Existence: The steady state exists if there is $k_{N C}^{*}>0$ such that $G\left(k_{N C}^{*}\right)=0 . G(k)$ is a continuous function of $k \in(0, \tilde{k})$ with $G(k)>0$ for $k<k^{+}$. Also $G\left(k^{+}\right)=v^{\prime}(.) / u^{\prime}()>$.0 and $G(\tilde{k})=-\rho<0$ as $v^{\prime}(\infty)=0$. Hence, there exists $k_{N C}^{*} \in\left(k^{+}, \tilde{k}\right)$ with $G\left(k_{N C}^{*}\right)=0$.

Uniqueness: The arguments of Proposition 1 apply accordingly. A sufficient condition for uniqueness is given by $G^{\prime}\left(k_{N C}^{*}\right)<0$ for all $k_{N C}^{*}$ with $G\left(k_{N C}^{*}\right)=0$ or equivalently

$$
\begin{gathered}
{\left[\rho+\delta-f^{\prime}\left(k_{N C}^{*}\right)\right]\left[f^{\prime}\left(k_{N C}^{*}\right)-\delta\right]<f^{\prime \prime}\left(k_{N C}^{*}\right) \frac{u^{\prime}\left(c_{N C}^{*}\right)}{u^{\prime \prime}\left(c_{N C}^{*}\right)}+\frac{v^{\prime \prime}\left(a_{N C}^{*}\right)}{u^{\prime \prime}\left(c_{N C}^{*}\right)}\left[1+\frac{d q_{N C}^{*}}{d k_{N C}^{*}}\right],} \\
\text { where } \frac{d q_{N C}^{*}}{d k_{N C}^{*}}=-\frac{z f^{\prime \prime}\left(k_{N C}^{*}\right)}{\left[f^{\prime}\left(k_{N C}^{*}\right)-\delta\right]^{2}}>0
\end{gathered}
$$

Note that condition (C.2) is less restrictive than condition (A.2) in the benchmark model as the additional term is strictly positive.

Effects on $k$ and $r$ : Let $\bar{r}$ and $\bar{k}$ denote the steady state real rate and capital stock in the benchmark model and $r_{N C}^{*}$ and $k_{N C}^{*}$ in the model with land. For $\bar{r} \leq 0$, it follows directly from Proposition 2 that $r_{N C}^{*}>0 \geq \bar{r}$ and from (19) that $k_{N C}^{*}<\tilde{k} \leq \bar{k}$.

\footnotetext{
${ }^{37}$ If land depreciates at rate $\tau$, we must have $r>-\tau$. See Michau et al. (2017) for the general case.
} 
Let $\bar{r}>0$ and $\bar{k}<\tilde{k}$. In the model with land, $k_{N C}^{*}$ defines $q_{N C}^{*}=q\left(k_{N C}^{*}\right)>0$. Consider the rise in $q$ from zero to $q_{N C}^{*}$ as exogenous and recover the effects on $k$ from $\Omega(k, q)=0$ in

$$
\Omega(k, q)=f^{\prime}(k)-\delta-\rho+\frac{v^{\prime}(k+q)}{u^{\prime}(f(k)+z-\delta k)}=0,
$$

which is equivalent to $F(k)$ in (A.1) except it includes $q$ in $v(a)$. It follows that

$$
\frac{d k}{d q}=-\frac{\partial \Omega / \partial q}{\partial \Omega / \partial k}=\frac{-v^{\prime \prime}(k+q) u^{\prime}(c)}{F^{\prime}(k)}<0
$$

as $F^{\prime}(\bar{k})<0$ by (A.2). Therefore, $k_{N C}^{*}<\bar{k}<\tilde{k}$ and $r_{N C}^{*}>\bar{r}>0$.

Stability: The dynamic system is given by (2) for the land price, (14) for consumption and (18) for the capital stock with $L_{t}=1$ for a given initial $k_{0}>0$ as

$$
\begin{gathered}
\dot{c}_{t}=\frac{c_{t}}{\eta_{c}}\left[f^{\prime}\left(k_{t}\right)-\delta-\rho+\frac{v^{\prime}\left(k_{t}+q_{t}\right)}{u^{\prime}\left(c_{t}\right)}\right], \\
\dot{k}_{t}=f\left(k_{t}\right)-\delta k_{t}+z-c_{t}, \\
\dot{q}_{t}=\left[f^{\prime}\left(k_{t}\right)-\delta\right] q_{t}-z,
\end{gathered}
$$

where I used (5) and (9) to substitute for the real rate in (2) and (14). Log-linearization of this system around the steady state via a first-order Taylor approximation gives

$$
\left(\begin{array}{c}
\dot{c}_{t} \\
\dot{k}_{t} \\
\dot{q}_{t}
\end{array}\right)=\left(\begin{array}{ccc}
\rho+\delta-f^{\prime}\left(k_{N C}^{*}\right) & -\frac{u^{\prime}\left(c_{N C}^{*}\right)}{u^{\prime \prime}\left(c_{N C}^{*}\right)}\left[f^{\prime \prime}\left(k_{N C}^{*}\right)+\frac{v^{\prime \prime}\left(a_{N C}^{*}\right)}{u^{\prime}\left(c_{N C}^{N}\right)}\right] & -\frac{v^{\prime \prime}\left(a_{N C}^{*}\right)}{u^{\prime \prime}\left(c_{N C}^{N}\right)} \\
-1 & f^{\prime}\left(k_{N C}^{*}\right)-\delta & 0 \\
0 & \frac{z f^{\prime \prime}\left(k_{N C}^{*}\right)}{f^{\prime}\left(k_{N C}^{*}\right)-\delta} & f^{\prime}\left(k_{N C}^{*}\right)-\delta
\end{array}\right)\left(\begin{array}{l}
c_{t}-c_{N C}^{*} \\
k_{t}-k_{N C}^{*} \\
q_{t}-q_{N C}^{*}
\end{array}\right),
$$

where I use the definition of $\eta_{c}$. The eigenvalues of the transition matrix solve

$$
\begin{gathered}
\Lambda(\lambda)=-\lambda^{3}+\left[\rho+f^{\prime}\left(k_{N C}^{*}\right)-\delta\right] \lambda^{2}-\Omega_{1} \lambda-\left[f^{\prime}\left(k_{N C}^{*}\right)-\delta\right] \frac{u^{\prime}\left(c_{N C}^{*}\right)}{u^{\prime \prime}\left(c_{N C}^{*}\right)} G^{\prime}\left(k_{N C}^{*}\right)=0, \\
\text { where } \Omega_{1} \equiv \rho\left[f^{\prime}\left(k_{N C}^{*}\right)-\delta\right]-\frac{u^{\prime}\left(c_{N C}^{*}\right)}{u^{\prime \prime}\left(c_{N C}^{*}\right)} F^{\prime}\left(k_{N C}^{*}\right)
\end{gathered}
$$

with $F^{\prime}\left(k_{N C}^{*}\right)<0$ from (A.2) and $G^{\prime}\left(k_{N C}^{*}\right)<0$ from (C.2). Let $\varphi_{i}$ denote the eigenvalues of the system.

I rewrite the equation in terms of its solutions as $\Lambda(\lambda)=\left(\varphi_{1}-\lambda\right)\left(\varphi_{2}-\lambda\right)\left(\varphi_{3}-\lambda\right)$ or

$$
\Lambda(\lambda)=-\lambda^{3}+\left(\varphi_{1}+\varphi_{2}+\varphi_{3}\right) \lambda^{2}-\left(\varphi_{1} \varphi_{2}+\varphi_{1} \varphi_{3}+\varphi_{2} \varphi_{3}\right) \lambda+\varphi_{1} \varphi_{2} \varphi_{3}=0 .
$$


Matching terms of these two equations defines the eigenvalues as

$$
\begin{gathered}
\varphi_{1}+\varphi_{2}+\varphi_{3}=\rho+f^{\prime}\left(k_{N C}^{*}\right)-\delta>0, \\
\varphi_{1} \varphi_{2} \varphi_{3}=-\left[f^{\prime}\left(k_{N C}^{*}\right)-\delta\right] \frac{u^{\prime}\left(c_{N C}^{*}\right)}{u^{\prime \prime}\left(c_{N C}^{*}\right)} G^{\prime}\left(k_{N C}^{*}\right)<0 .
\end{gathered}
$$

At least one eigenvalue is positive by (C.7), whereas (C.8) implies one or three negative eigenvalues. Hence, there is exactly one negative eigenvalue and the system exhibits saddle-point stability.

\section{Proof of Proposition 6}

Define $k^{+}, \tilde{k}$ and $\hat{k}$ as before with $k^{+}<\tilde{k}<\hat{k} . G(k)$ is given in (C.1) with $v^{\prime}(a) \geq \beta$ and represents conditions (26) in the bubbly and (27) in the fundamental steady state.

Existence and Uniqueness: The steady state exists if there exists $k_{N C}^{*}>0$ such that $G\left(k_{N C}^{*}\right)=0$ in (C.1). $G(k)$ is continuous in $k \in(0, \hat{k})$ since $v^{\prime}(a)=\beta$ for $k \geq \tilde{k}$. However, $k_{N C}^{*} \in(0, \tilde{k})$ by Proposition 2. We have $G(k)>0$ for $k<k^{+}$and $G\left(k^{+}\right)=v^{\prime}(.) / u^{\prime}()>$.0 . Existence requires $G(\tilde{k})=\rho-\beta / u^{\prime}(c(\tilde{k}))<0$ or equivalently

$$
G(\tilde{k})<0 \quad \leftrightarrow \quad \beta<\rho u^{\prime}(c(\tilde{k}))
$$

This is condition (24) in Proposition $6{ }^{38}$ Uniqueness requires $G^{\prime}\left(k_{N C}^{*}\right)<0$ for all $k_{N C}^{*}$ with $G\left(k_{N C}^{*}\right)=0$. Hence, uniqueness condition (C.2) applies accordingly.

Suppose instead $G\left(k_{N C}^{*}\right)=0$ at $k_{N C}^{*} \in(\tilde{k}, \hat{k})$. Existence follows from Proposition 1 with $v^{\prime}(a)=\beta$. Let

$$
\Psi(k, L) \equiv f^{\prime}(k)-\delta-\rho+\frac{\beta}{u^{\prime}([f(k)-\delta k] L+z)},
$$

with $L \in(0,1)$ and $\Psi\left(k_{N C}^{*}, L\right)=0$ in steady state. We have

$$
\frac{d k}{d L}=-\frac{\partial \Psi / \partial L}{\partial \Psi / \partial k}=\frac{\beta u^{\prime \prime}\left(c_{N C}^{*}\right)\left[f\left(k_{N C}^{*}\right)-\delta k_{N C}^{*}\right]}{\left[u^{\prime}\left(c_{N C}^{*}\right)\right]^{2}} \frac{1}{\partial \Psi / \partial k}>0
$$

as $k_{N C}^{*}<\hat{k}$ and $\frac{\partial \Psi}{\partial k}<0$ from (A.2). Hence, a decline in $L$ lowers $k_{N C}^{*}$. A stagnation steady state is defined for any $L \in(0,1)$ that satisfies

$$
\Psi(\tilde{k}, L)<0 \quad \leftrightarrow \quad \rho u^{\prime}([f(\tilde{k})-\delta \tilde{k}] L+z)>\beta
$$

\footnotetext{
${ }^{38}$ Intuitively, full employment requires that the natural rate $r^{N}$ at $\tilde{k}$ is above the return on savings $r^{S}$, which is zero at $\tilde{k}$. Then an intersection in $k^{+}<k_{N C}^{*}<\tilde{k}$ is ensured as both functions are continuous in this region.
} 
and takes into account the non-negativity restriction $L>0$. Taken together, this implies

$$
\rho u^{\prime}(z)>\beta
$$

Stability: In the fundamental steady state, the bubble component is always zero as it would otherwise grow infinitely as $r_{N C}^{*}>0$. Hence, $\dot{q}=0$ in steady state and real wealth is constant. The dynamic system is given by (C.4), (C.5) and (C.6) and the stability patterns are identical to the case of $\beta=0$ in the previous proof.

In the bubbly steady state, we have $\dot{a}_{t}>0$ as $\dot{q}_{t}^{B}>0$ for given $q_{0}^{B}>0$ and $v^{\prime}\left(a_{t}\right)=\beta$ in (C.4). Denote $x_{t}=1 / q_{t}^{B}$ with $x_{N C}^{*}=0$ in steady state. The bubble equation (4) becomes

$$
\dot{x}_{t}=-\left[f^{\prime}\left(k_{t}\right)-\delta\right] x_{t},
$$

where I use (5) and (9) to substitute for $r_{t}^{B}$. The dynamic system is given by (C.4) with $v^{\prime}\left(a_{t}\right)=\beta$, (C.5), (C.6) for the fundamental price $q_{t}^{F}$ and (D.5) for the bubble. A first-order Taylor approximation around the bubbly steady state gives

$$
\left(\begin{array}{c}
\dot{c}_{t} \\
\dot{k}_{t} \\
\dot{q}_{t}^{F} \\
\dot{x}_{t}
\end{array}\right)=\left(\begin{array}{cccc}
\rho+\delta-f^{\prime}\left(k_{N C}^{*}\right) & -\frac{u^{\prime}\left(c_{N C}^{*}\right)}{u^{\prime \prime}\left(c_{N C}^{*}\right)} f^{\prime \prime}\left(k_{N C}^{*}\right) & 0 & 0 \\
-1 & f^{\prime}\left(k_{N C}^{*}\right)-\delta & 0 & 0 \\
0 & \frac{z f^{\prime \prime}\left(k_{N C}^{*}\right)}{f^{\prime}\left(k_{N C}^{*}\right)-\delta} & f^{\prime}\left(k_{N C}^{*}\right)-\delta & 0 \\
0 & 0 & 0 & -f^{\prime}\left(k_{N C}^{*}+\delta\right.
\end{array}\right)\left(\begin{array}{l}
c_{t}-c_{N C}^{*} \\
k_{t}-k_{N C}^{*} \\
q_{t}^{F}-q_{N C}^{F *} \\
x_{t}-x_{N C}^{*}
\end{array}\right),
$$

where I use the definition of $\eta_{c}$ and $v^{\prime \prime}(a)=0$. The eigenvalues of this system solve

$$
\Lambda(\lambda)=\left[-f^{\prime}\left(k_{N C}^{*}\right)+\delta-\lambda\right]\left[f^{\prime}\left(k_{N C}^{*}\right)-\delta-\lambda\right] \cdot\left\|\begin{array}{cc}
\rho+\delta-f^{\prime}\left(k_{N C}^{*}\right)-\lambda & -\frac{u^{\prime}\left(c_{N C}^{*}\right)}{u^{\prime \prime}\left(c_{N C}^{*}\right)} f^{\prime \prime}\left(k_{N C}^{*}\right) \\
-1 & f^{\prime}\left(k_{N C}^{*}\right)-\delta-\lambda
\end{array}\right\|=0,
$$

where $\|$.$\| denotes the determinant. From the proof of Proposition 1$ with $v^{\prime \prime}(a)=0$ it follows that this matrix has one positive and one negative eigenvalue. In addition, $\lambda_{3}=f^{\prime}\left(k_{N C}^{*}\right)-\delta>0$ and $\lambda_{4}=-\left[f^{\prime}\left(k_{N C}^{*}\right)-\delta\right]<0$. The bubbly equilibrium hence satisfies saddle-point stability. For given $k_{0}>0$ and $q_{0}^{B}>0$, which determine $c\left(k_{0}, q_{0}^{B}\right)$ and $q^{F}\left(k_{0}, q_{0}^{B}\right)$, the model converges to the steady state along the unique saddle path. 


\section{E $\quad$ Proof of Proposition 7}

Define $k^{+}, \tilde{k}$ and $\hat{k}$ as before with $k^{+}<\tilde{k}<\hat{k}$. The steady state real money stock under full employment is defined by (38) and (40) as a function of the capital stock as

$$
m(k)=\omega^{\prime-1}\left(\left[f^{\prime}(k)-\delta+\mu\right] u^{\prime}(f(k)-\delta k+z)\right) .
$$

with $m^{\prime}(k)>0$ and $m(k) \rightarrow \infty$ for $k \rightarrow k_{\mu}$, where $k_{\mu}$ satisfies $f^{\prime}\left(k_{\mu}\right)=\delta-\mu$. Hence, $k_{\mu}>\tilde{k}$ for $\mu>0$ and vice versa.

Monetary Wealth Preferences: Consider first the case of money in $v(\tilde{a})=v(a)$. Full employment condition (42) and (E.1) define $H(k)$ as

$$
H(k) \equiv f^{\prime}(k)-\delta-\rho+\frac{v^{\prime}\left(k+\frac{z}{f^{\prime}(k)-\delta}+m(k)\right)}{u^{\prime}(f(k)-\delta k+z)} .
$$

(i) Existence: The steady state exists if there exists $k^{*}>0$ such that $H\left(k^{*}\right)=0 . H(k)$ is continuous in $k \in(0, \tilde{k})$ if $\mu \geq 0$ or $k \in\left(0, k_{\mu}\right)$ if $\mu<0$. It holds that $H(k)>0$ for $k<k^{+}$. Hence, we cannot have $k^{*} \in\left(0, k^{+}\right)$, which requires $k_{\mu}>k^{+}$or $\mu>-\rho$. Also $H\left(k^{+}\right)=v^{\prime}(.) / u^{\prime}()>$.0 . If $\mu \geq 0, H(\tilde{k})=-\rho<0$ and there exists $k^{*}$ in $(0, \tilde{k})$ with $H\left(k^{*}\right)=0$. If $\mu<0, H\left(k_{\mu}\right)=-\rho<0$ as $m(k) \rightarrow \infty$ and there exists $k^{*}$ in $\left(0, k_{\mu}\right)$ with $H\left(k^{*}\right)=0$ unless $\mu<-\rho$. Hence, existence requires $\mu<-\rho$ for $v(\tilde{a})=v(a)$.

(ii) Uniqueness: A sufficient condition is $H^{\prime}\left(k^{*}\right)<0$ for all $k^{*}$ with $H\left(k^{*}\right)=0$ or

$$
\begin{gathered}
{\left[\rho+\delta-f^{\prime}\left(k^{*}\right)\right]\left[f^{\prime}\left(k^{*}\right)-\delta\right]<f^{\prime \prime}\left(k^{*}\right) \frac{u^{\prime}\left(c^{*}\right)}{u^{\prime \prime}\left(c^{*}\right)}+\frac{v^{\prime \prime}\left(a^{*}\right)}{u^{\prime \prime}\left(c^{*}\right)}\left[1+\frac{d q^{*}}{d k^{*}}+\frac{d m^{*}}{d k^{*}}\right],} \\
\text { where } \frac{d q^{*}}{d k^{*}}=-\frac{z f^{\prime \prime}\left(k^{*}\right)}{\left[f^{\prime}\left(k^{*}\right)-\delta\right]^{2}}>0 \\
\text { and } \frac{d m^{*}}{d k^{*}}=\frac{1}{\omega^{\prime \prime}\left(m^{*}\right)}\left[\left(f^{\prime}\left(k^{*}\right)-\delta\right)\left(f^{\prime}\left(k^{*}\right)-\delta+\mu\right) u^{\prime \prime}\left(c^{*}\right)+f^{\prime \prime}\left(k^{*}\right) u^{\prime}\left(c^{*}\right)\right]>0,
\end{gathered}
$$

for all $k^{*}$ with $H\left(k^{*}\right)=0$. This condition is less restrictive than (A.2) or (C.2) since the additional term is positive.

(iii) Impossibility of Secular Stagnation: Under stagnation, we have $\pi=-\gamma<0$ in steady state and therefore $\dot{m}>0$ as $\mu+\gamma>0$. Then $i=0$ and $v^{\prime}(a)=0$. Secular stagnation condition (44) then requires $\gamma=\rho$. However, the steady state is not well-defined as $K, L$ and $c$ are indeterminate in this case and the transversality condition is violated for $\mu \geq 0$. 
Non-monetary wealth preferences: With $v(\tilde{a})=v\left(a-m^{S}\right), H(k)$ is identical to $G(k)$ in (C.1). This implies $r_{N C}^{*} \in(0, \rho)$ and $k_{N C}^{*} \in\left(k^{+}, \tilde{k}\right)$. As $k^{*}$ is uniquely determined by $G(k)$ if (C.2) holds, $P$ adjusts to clear the money market. From (41), define

$$
J(P)=\frac{\omega^{\prime}\left(M^{S} / P\right)}{u^{\prime}\left(f\left(k^{*}\right)-\delta k^{*}+z\right)}-\mu-r_{N C}^{*}
$$

Full employment requires $J(P)=0 . J(P)$ is continuous and strictly increasing in $P$ for a given $M^{S}$. It holds that $J(\infty)=\infty>0$ and $J(0)=-\mu-r_{N C}^{*}$. Existence requires $J(0)<0$ or equivalently $\mu>-r_{N C}^{*}$. Hence, we have $\mu>-r_{N C}^{*}$ in (44) for $v(\tilde{a})=v\left(a-m^{S}\right)$. As $J^{\prime}(P)>0$, the full employment steady state is unique if (C.2) holds.

Stability: The dynamic system is given by (C.4), (C.5), (C.6) and (29), where $m_{t}$ is potentially included in (C.4). There are no bubbles with $\beta=0$. Using (30) to substitute for $\pi_{t}$, (38) for $i_{t}$ and (9) for $r_{t},(29)$ is rewritten as

$$
\dot{m}_{t}=\left[\mu-\frac{\omega^{\prime}\left(m_{t}\right)}{u^{\prime}\left(c_{t}\right)}+f^{\prime}\left(k_{t}\right)-\delta\right] m_{t}
$$

A first-order Taylor approximation around the full employment steady state gives

$$
\left(\begin{array}{c}
\dot{c}_{t} \\
\dot{k}_{t} \\
\dot{q}_{t} \\
\dot{m}_{t}
\end{array}\right)=\left(\begin{array}{cccc}
\rho+\delta-f^{\prime}\left(k^{*}\right) & -\frac{u^{\prime}\left(c^{*}\right) f^{\prime \prime}\left(k^{*}\right)}{u^{\prime \prime}\left(c^{*}\right)}-\frac{v^{\prime \prime}\left(\tilde{a}^{*}\right)}{u^{\prime \prime}\left(c^{*}\right)} & -\frac{v^{\prime \prime}\left(\tilde{a}^{*}\right)}{u^{\prime \prime}\left(c^{*}\right)} & -\frac{v^{\prime \prime}\left(\tilde{a}^{*}\right)}{u^{\prime \prime}\left(c^{*}\right)} \\
-1 & f^{\prime}\left(k^{*}\right)-\delta & 0 & 0 \\
0 & \frac{z f^{\prime \prime}\left(k^{*}\right)}{f^{\prime}\left(k^{*}\right)-\delta} & f^{\prime}\left(k^{*}\right)-\delta & 0 \\
\frac{\omega^{\prime}\left(m^{*}\right) u^{\prime \prime}\left(c^{*}\right)}{\left[u^{\prime}\left(c^{*}\right)\right]^{2}} m^{*} & f^{\prime \prime}\left(k^{*}\right) m^{*} & 0 & -\frac{\omega^{\prime \prime}\left(m^{*}\right)}{u^{\prime}\left(c^{*}\right)} m^{*}
\end{array}\right)\left(\begin{array}{c}
c_{t}-c^{*} \\
k_{t}-k^{*} \\
q_{t}-q^{*} \\
m_{t}-m^{*}
\end{array}\right)
$$

where I use the definition of $\eta_{c}$. The eigenvalues of the system solve

$$
\begin{gathered}
{\left[-\frac{\omega^{\prime \prime}\left(m^{*}\right)}{u^{\prime}\left(c^{*}\right)} m^{*}-\lambda\right] \cdot\left\|\begin{array}{ccc}
\rho+\delta-f^{\prime}\left(k^{*}\right)-\lambda & -\frac{u^{\prime}\left(c^{*}\right)}{u^{\prime \prime}\left(c^{*}\right)}\left[f^{\prime \prime}\left(k^{*}\right)+\frac{v^{\prime \prime}\left(\tilde{a}^{*}\right)}{u^{\prime \prime}\left(c^{*}\right)}\right] & -\frac{v^{\prime \prime}\left(\tilde{a}^{*}\right)}{u^{\prime \prime}\left(c^{*}\right)} \\
-1 & f^{\prime}\left(k^{*}\right)-\delta-\lambda & 0 \\
0 & \frac{z f^{\prime \prime}\left(k^{*}\right)}{f^{\prime}\left(k^{*}\right)-\delta} & f^{\prime}\left(k^{*}\right)-\delta-\lambda
\end{array}\right\|} \\
+\frac{\omega^{\prime}\left(m^{*}\right) u^{\prime \prime}\left(c^{*}\right)}{\left[u^{\prime}\left(c^{*}\right)\right]^{2}} m^{*}\left[f^{\prime}\left(k^{*}\right)-\delta-\lambda\right]^{2} \frac{v^{\prime \prime}\left(\tilde{a}^{*}\right)}{u^{\prime \prime}\left(c^{*}\right)}+f^{\prime \prime}\left(k^{*}\right) m^{*} \frac{v^{\prime \prime}\left(\tilde{a}^{*}\right)}{u^{\prime \prime}\left(c^{*}\right)}\left[f^{\prime}\left(k^{*}\right)-\delta-\lambda\right]=0,
\end{gathered}
$$

where $\|$.$\| denotes the determinant. The eigenvalues \varphi_{i}$ of the transition matrix then solve $\Lambda(\lambda)=\left(\varphi_{1}-\lambda\right)\left(\varphi_{2}-\lambda\right)\left(\varphi_{3}-\lambda\right)\left(\varphi_{4}-\lambda\right)=0$, which is a quartic equation in $\lambda$. Matching terms implies that the eigenvalues are related as

$$
\varphi_{1} \varphi_{2} \varphi_{3} \varphi_{4}=-\left[f^{\prime}\left(k^{*}\right)-\delta\right] \frac{\omega^{\prime \prime}\left(m^{*}\right)}{u^{\prime}\left(c^{*}\right)} m^{*} H^{\prime}\left(k^{*}\right)<0
$$


where $H(k)$ is defined in (E.2) and $H^{\prime}\left(k^{*}\right)<0$ follows from condition (E.3). Hence, the dynamic system has either one or three negative eigenvalues. In addition, we have

$$
\begin{gathered}
\varphi_{1}+\varphi_{2}+\varphi_{3}+\varphi_{4}=-\frac{\omega^{\prime \prime}\left(m^{*}\right)}{u^{\prime}\left(c^{*}\right)} m^{*}+2\left[f^{\prime}\left(k^{*}\right)-\delta\right]+\left[\rho+\delta-f^{\prime}\left(k^{*}\right)\right]>0, \\
\left(\varphi_{1}+\varphi_{2}\right) \varphi_{3} \varphi_{4}+\left(\varphi_{3}+\varphi_{4}\right) \varphi_{1} \varphi_{2}=-\left[f^{\prime}\left(k^{*}\right)-\delta\right] \frac{u^{\prime}\left(c^{*}\right)}{u^{\prime \prime}\left(c^{*}\right)} G^{\prime}\left(k^{*}\right)-\frac{\omega^{\prime \prime}\left(m^{*}\right)}{u^{\prime}\left(c^{*}\right)} m^{*} \Omega_{1} \\
+\frac{v^{\prime \prime}\left(\tilde{a}^{*}\right)}{u^{\prime}\left(c^{*}\right)} m^{*}\left(2\left[f^{\prime}\left(k^{*}\right)-\delta\right]\left[f^{\prime}\left(k^{*}\right)-\delta+\mu\right]+f^{\prime \prime}\left(k^{*}\right) \frac{u^{\prime}\left(c^{*}\right)}{u^{\prime \prime}\left(c^{*}\right)}\right)<0,
\end{gathered}
$$

where the negative sign follows from $G^{\prime}\left(k^{*}\right)<0$ in (C.2) and from the proof of Proposition 4. Suppose there are three negative and one positive eigenvalue, $\varphi_{4}>0$. Solving the two equations for $\varphi_{4}$ gives

$$
\begin{gathered}
-\left[\varphi_{1}+\varphi_{2}+\varphi_{3}\right]<\varphi_{4}<-\frac{\varphi_{1} \varphi_{2} \varphi_{3}}{\left(\varphi_{1}+\varphi_{2}\right) \varphi_{3}+\varphi_{1} \varphi_{2}} \\
{\left[\varphi_{1}+\varphi_{2}+\varphi_{3}\right]\left(\varphi_{1}+\varphi_{2}\right) \varphi_{3}+\left[\varphi_{1}+\varphi_{2}+\varphi_{3}\right] \varphi_{1} \varphi_{2}>\varphi_{1} \varphi_{2} \varphi_{3}} \\
\left(\varphi_{1}+\varphi_{2}\right)\left[\left(\varphi_{1}+\varphi_{2}+\varphi_{3}\right) \varphi_{3}+\varphi_{1} \varphi_{2}\right]>0
\end{gathered}
$$

which contradicts the assumption of three negative eigenvalues. Hence, the system has exactly one negative eigenvalue and is saddle-point stable around the steady state.

\section{F Proof of Proposition 8}

Define $k^{+}, \tilde{k}$ and $\hat{k}$ as before with $k^{+}<\tilde{k}<\hat{k} . k_{\mu}$ satisfies $f^{\prime}\left(k_{\mu}\right)=\delta-\mu$ and $H(k)$ is defined in (E.2) as a continuous function of $k \in(0, \tilde{k})$ if $\mu \geq 0$ or $k \in\left(0, k_{\mu}\right)$ if $\mu<0$.

Full Employment Steady State: Existence requires $H(k)=0$ for some $k \in(0, \tilde{k})$ if $\mu \geq 0$ or $k \in\left(0, k_{\mu}\right)$ if $\mu<0$. It holds that $H(k)>0$ for $k<k^{+}$. Hence, we cannot have $k^{*} \in\left(0, k^{+}\right)$, which requires $k_{\mu}>k^{+}$or equivalently $\mu>-\rho$. Also $H\left(k^{+}\right)=\tilde{v}^{\prime}(.) / u^{\prime}()>$.0 . If $\mu \geq 0$, existence requires

$$
H(\tilde{k})<0 \quad \leftrightarrow \quad \beta<\rho u^{\prime}(c(\tilde{k}))
$$

Then there exists at least one $k^{*} \in(0, \tilde{k})$ with $H\left(k^{*}\right)=0$. If $\mu<0$ and $v(\tilde{a})=v(a)$, full employment requires

$$
H\left(k_{\mu}\right)<0 \leftrightarrow \beta<(\rho+\mu) u^{\prime}\left(c\left(k_{\mu}\right)\right)
$$

Then, there exists at least one $k^{*} \in\left(0, k_{\mu}\right)$ with $H\left(k^{*}\right)=0$ unless $\mu<-\rho$. For the case of $\mu<0$ and $v(\tilde{a})=v\left(a-m^{S}\right)$, the proof is identical to Proposition 7 . 
Uniqueness requires $H^{\prime}\left(k^{*}\right)<0$ for all $k^{*}$ that satisfy $H\left(k^{*}\right)=0$, which is expressed in conditions (C.2) and (E.3). In addition, the stability properties under full employment are identical to the case of $\beta=0$ before.

Secular Stagnation Steady State: A secular stagnation steady state exists if (43) holds. Then, $k=k^{*}$, where $k^{*}$ satisfies $f^{\prime}\left(k^{*}\right)=\delta+\gamma$. Define $M(L)$ by (43) with $k=k^{*}$ as

$$
M(L)=\gamma-\rho+\frac{v^{\prime}(\tilde{a})}{u^{\prime}\left(\left[f\left(k^{*}\right)-\delta k^{*}\right] L+z\right)} .
$$

$M(L)$ is continuous in $L$. The secular stagnation steady state exists if there is $0<L<1$ such that $M(L)=0$.

If $v(\tilde{a})=v(a)$ or if $q^{B}>0, v^{\prime}(\tilde{a})=\beta$ in (F.3) and we have $M^{\prime}(L)>0$. We require $M(L=0)<0<M(L=1)$ for an equilibrium to exist. This implies:

$$
\gamma-\rho+\frac{\beta}{u^{\prime}(z)}<0<\gamma-\rho+\frac{\beta}{u^{\prime}\left(f\left(k^{*}\right)-\delta k^{*}+z\right)}
$$

Uniqueness is guaranteed as $M^{\prime}(L)>0$. If $v(\tilde{a})=v\left(a-m^{S}\right)=v\left(k^{*} L+q^{S}\right)$, then $v^{\prime \prime}(\tilde{a})<0$. Existence of the secular stagnation steady state then requires

$$
\gamma-\rho+\frac{\left.v^{\prime}(z / \gamma)\right)}{u^{\prime}(z)}<0<\gamma-\rho+\frac{v^{\prime}\left(k^{*}+z / \gamma\right)}{u^{\prime}\left(f\left(k^{*}\right)-\delta k^{*}+z\right)}
$$

(F.4) and (F.5) are summarized in (46). Uniqueness requires $M^{\prime}(L)>0$ at $L=L^{S}$ or equivalently

$$
M^{\prime}(L)>0 \leftrightarrow(\rho-\gamma) \frac{f\left(k^{*}\right)-\delta k^{*}}{k^{*}}>\frac{v^{\prime \prime}\left(a^{S}\right)}{u^{\prime \prime}\left(c^{S}\right)}
$$

which implies that a reduction in the labor input increases the natural interest rate.

Stability of the Stagnation Steady State: It holds that $L_{t}<1$ and $k_{t}>K_{t}$. Inflation and the price level are determined by the nominal wage rigidity. Hence, $m_{t}$ becomes pre-determined and evolves with $\mu-\pi_{t}$. Inflation is given by (33), (39) and (40) as

$$
\pi_{t}=-\gamma-\frac{\dot{w}_{t}}{w_{t}}=-\gamma+\frac{f^{\prime \prime}\left(k_{t}\right) k_{t}}{f\left(k_{t}\right)-k_{t} f^{\prime}\left(k_{t}\right)} \dot{k}_{t}=\frac{\omega^{\prime}\left(m_{t}\right)}{u^{\prime}\left(c_{t}\right)}-f^{\prime}\left(k_{t}\right)+\delta
$$

This determines the dynamics of the capital-labor ratio $k_{t}$ and those of $L_{t}$ together with $\dot{K}_{t}$ in (17). As $m_{t} \rightarrow \infty$, let $x_{t}=1 / m_{t}$ with $x_{t} \rightarrow 0$. For $v(\tilde{a})=v(a)$, the dynamic system is given by

$$
\dot{c}_{t}=\frac{c_{t}}{\eta_{c}}\left[f^{\prime}\left(k_{t}\right)-\delta-\rho+\frac{v^{\prime}\left(K_{t}+q_{t}+1 / x_{t}\right)}{u^{\prime}\left(c_{t}\right)}\right]
$$




$$
\begin{gathered}
\dot{K}_{t}=\left[f\left(k_{t}\right)-\delta k_{t}\right] \frac{K_{t}}{k_{t}}+z-c_{t}, \\
\dot{k}_{t}=\frac{f\left(k_{t}\right)-k_{t} f^{\prime}\left(k_{t}\right)}{f^{\prime \prime}\left(k_{t}\right) k_{t}}\left[\frac{\omega^{\prime}\left(1 / x_{t}\right)}{u^{\prime}\left(c_{t}\right)}-f^{\prime}\left(k_{t}\right)+\delta+\gamma\right] \\
\dot{q}_{t}=\left[f^{\prime}\left(k_{t}\right)-\delta\right] q_{t}-z, \\
\dot{x}_{t}=\left[-\mu-f^{\prime}\left(k_{t}\right)+\delta+\frac{\omega^{\prime}\left(1 / x_{t}\right)}{u^{\prime}\left(c_{t}\right)}\right] x_{t},
\end{gathered}
$$

A first-order Taylor approximation around the stagnation steady state gives

$$
\left(\begin{array}{c}
\dot{c}_{t} \\
\dot{K}_{t} \\
\dot{k}_{t} \\
\dot{q}_{t} \\
\dot{m}_{t}
\end{array}\right)=\left(\begin{array}{ccccc}
\rho-\gamma & 0 & -\frac{u^{\prime}\left(c^{*}\right) f^{\prime \prime}\left(k^{*}\right)}{u^{\prime \prime}\left(c^{*}\right)} & 0 & -\frac{v^{\prime \prime}\left(\tilde{a}^{*}\right)}{u^{\prime \prime}\left(c^{*}\right)} \frac{1}{x^{* 2}} \\
-1 & \frac{f\left(k^{*}\right)}{k^{*}}-\delta & \frac{f^{\prime}\left(k^{*}\right) k^{*}-f\left(k^{*}\right)}{k^{*}} \frac{K^{*}}{k^{*}} & 0 & 0 \\
0 & 0 & \frac{k^{*} f^{\prime}\left(k^{*}\right)-f\left(k^{*}\right)}{k^{*}} & 0 & -\frac{f\left(k^{*}\right)-k^{*} f^{\prime}\left(k^{*}\right)}{f^{\prime \prime}\left(k^{*}\right) k^{*}} \frac{\omega^{\prime \prime}\left(m^{*}\right)}{u^{\prime}\left(c^{*}\right)} \frac{1}{x^{* 2}} \\
0 & 0 & f^{\prime \prime}\left(k^{*}\right) q^{*} & \gamma & 0 \\
0 & 0 & 0 & 0 & -\gamma-\mu
\end{array}\right)\left(\begin{array}{c}
c_{t}-c^{*} \\
K_{t}-K^{*} \\
k_{t}-k^{*} \\
q_{t}-q^{*} \\
x_{t}-x^{*}
\end{array}\right),
$$

where I use $f^{\prime}\left(k^{*}\right)-\delta=\gamma, v^{\prime \prime}(\tilde{a})=0$ and $\omega^{\prime}(m)=0$. The eigenvalues solve

$$
(-\gamma-\mu-\lambda)\left(\frac{k^{*} f^{\prime}\left(k^{*}\right)-f\left(k^{*}\right)}{k^{*}}-\lambda\right)(\gamma-\lambda)(\rho-\gamma-\lambda)\left(\frac{f\left(k^{*}\right)}{k^{*}}-\delta-\lambda\right)=0 .
$$

Hence, three eigenvalues, $\lambda_{1}=\gamma, \lambda_{2}=\frac{f\left(k^{*}\right)}{k^{*}}-\delta$ and $\lambda_{3}=\rho-\gamma$, are positive, while two eigenvalues, $\lambda_{4}=-\gamma-\mu$ and $\lambda_{5}=\frac{k^{*} f^{\prime}\left(k^{*}\right)-f\left(k^{*}\right)}{k^{*}}$, are negative. The system is saddle-path stable around the asymptotic steady state under persistent stagnation.

For $v(\tilde{a})=v\left(a-m^{S}\right)$, we have $v^{\prime \prime}(\tilde{a})<0$. Then $\lambda_{1}=\gamma>0, \lambda_{2}=\frac{f^{\prime}\left(k^{*}\right) k^{*}-f\left(k^{*}\right)}{k^{*}}<0$ and $\lambda_{3}=-\gamma-\mu<0$ are unchanged to above. The remaining two eigenvalues are recovered from

$$
\lambda^{2}-\left[\rho-\gamma+\frac{f\left(k^{*}\right)}{k^{*}}-\delta\right] \lambda+(\rho-\gamma) \frac{f\left(k^{*}-\delta k^{*}\right)}{k^{*}}-\frac{v^{\prime \prime}\left(\tilde{a}^{*}\right)}{u^{\prime \prime}\left(c^{*}\right)}=0
$$

which can be rewritten as $\lambda^{2}-\left[\lambda_{4}+\lambda_{5}\right] \lambda+\lambda_{4} \lambda_{5}=0$. Matching terms implies that

$$
\lambda_{4} \lambda_{5}=(\rho-\gamma) \frac{f\left(k^{*}-\delta k^{*}\right)}{k^{*}}-\frac{v^{\prime \prime}\left(\tilde{a}^{*}\right)}{u^{\prime \prime}\left(c^{*}\right)}>0
$$

which follows from $M^{\prime}(L)>0$ in (F.6). Hence, $\lambda_{4}>0$ and $\lambda_{5}>0$. We have three positive and two negative eigenvalues and the stability patterns are identical to $v^{\prime \prime}(\tilde{a})=0$.

The proofs of Proposition 9 and 10 are equivalent to the proofs of Proposition 7 and 8 in Appendix E and $\mathrm{F}$ and not discussed in detail. 


\section{References}

Abel, Andrew B., Mankiw, N. Gregory, Summers, Lawrence H., and Zeckhauser, Richard J. (1989): "Assessing Dynamic Efficiency: Theory and Evidence". The Review of Economic Studies 56(1), pp. 1-19.

Bakshi, Gurdip S. and Chen, Zhiwu (1996): "The Spirit of Capitalism and Stock-Market Prices". American Economic Review 86(1), pp. 133-157.

Baldwin, Richard and Teulings, Coen (2014): Secular Stagnation: Facts, Causes and Cures. Vox eBook.

Becker, Robert (1980): "On the Long-Run Steady State in a Simple Dynamic Model of Equilibrium with Heterogeneous Households". The Quarterly Journal of Economics 95(2), pp. 375382.

Benhabib, Jess, Schmitt-Grohe, Stephanie, and Uribe, Martin (2001): "The Perils of Taylor Rules". Journal of Economic Theory 96(1-2), pp. 40-69.

Bernanke, Ben S. (2005): The Global Saving Glut and the U.S. Current Account Deficit. Speech

77. Board of Governors of the Federal Reserve System (U.S.)

Biswas, Siddhartha, Hanson, Andrew, and Phan, Toan (2017): Bubbly Recessions. Working Paper. University of North Carolina at Chapel Hill.

Bose, Sanjit (1971): "Optimal Growth and Wealth Effects: Comment". International Economic Review 12(1), pp. 157-160.

Caballero, Ricardo J. and Farhi, Emmanuel (2018): "The Safety Trap". Review of Economic Studies 85(1), pp. 223-274.

Caballero, Ricardo J., Farhi, Emmanuel, and Gourinchas, Pierre-Olivier (2016): Global Imbalances and Currency Wars at the ZLB. Working Paper 344401. Harvard University OpenScholar.

Diamond, Peter A. (1965): "National Debt in a Neoclassical Growth Model". American Economic Review 55(5), pp. 1126-1150.

Eggertsson, Gauti B. and Krugman, Paul (2012): "Debt, Deleveraging, and the Liquidity Trap: A Fisher-Minsky-Koo Approach". The Quarterly Journal of Economics 127(3), pp. 1469-1513.

Eggertsson, Gauti B., Mehrotra, Neil R., and Robbins, Jacob A. (2017): A Model of Secular Stagnation: Theory and Quantitative Evaluation. NBER Working Papers 23093. National Bureau of Economic Research, Inc.

Eggertsson, Gauti B., Mehrotra, Neil R., and Summers, Lawrence H. (2016): "Secular Stagnation in the Open Economy". American Economic Review 106(5), pp. 503-507. 
Eggertsson, Gauti B. and Woodford, Michael (2003): "The Zero Bound on Interest Rate and Optimal Monetary Policy". Brookings Papers on Economic Activity 34(1), pp. 139-235.

Geerolf, Francois (2017): Reassessing Dynamic Efficiency. Tech. rep. UCLA.

Hansen, Alvin H. (1939): "Economic Progress and Declining Population Growth ". American Economic Review 29(1), pp. 1-15.

Hanson, Andrew and Phan, Toan (2017): "Bubbles, Wage Rigidity, and Persistent Slumps". Economic Letters 151, pp. 66-70.

Homburg, Stefan (1991): "Interest and Growth in an Economy with Land". Canadian Journal of Economics 42(2), pp. 450-459.

- (2014): "Overaccumulation, Public Debt and the Importance of Land". German Economic Review 15(4), pp. 411-435.

Illing, Gerhard, Ono, Yoshiyasu, and Schlegl, Matthias (2017): Credit Booms, Debt Overhang and Secular Stagnation. ISER Discussion Paper 988. Institute of Social and Economic Research, Osaka University.

Kaminigashi, Takashi (2008): "The Spirit of Capitalism, Stock Market Bubbles and Output Fluctuations". International Journal of Economic Theory 4(1), pp. 3-28.

Keynes, John Maynard (1936): The General Theory of Employment, Interest and Money. London: Macmillan.

Kocherlakota, Narayana R. (2013): Impact of a Land Price Fall when Labor Markets are Incomplete. mimeo. Federal Reserve Bank of Minneapolis.

Krugman, Paul (1998): "It's Baaack: Japan's Slump and the Return of the Liquidity Trap". Brookings Papers on Economic Activity 2, pp. 137-187.

Kumhof, Michael, Rancière, Romain, and Winant, Pablo (2015): "Inequality, Leverage, and Crises". American Economic Review 105(3), pp. 1217-1245.

Kurz, Mordecai (1968): "Optimal Economic Growth and Wealth Effects". International Economic Review 9(3), pp. 348-357.

Michaillat, Pascal and Saez, Emmanuel (2014): An Economic Business-Cycle Model. NBER Working Paper No. 19777. National Bureau of Economic Research.

Michau, Jean-Baptiste (2017): Secular Stagnation: Theory and Remedies. Working Papers hal-01211667. HAL.

Michau, Jean-Baptiste, Ono, Yoshiyasu, and Schlegl, Matthias (2017): "Rational Bubbles and Ponzi Schemes in a Neoclassical Economy". unpublished manuscript.

Murota, Ryu-ichiro and Ono, Yoshiyasu (2011): "Growth, Stagnation and Status Preference". Metroeconomica 62(1), pp. 112-149. 
Nichols, Donald A. (1970): "Land and Economic Growth". American Economic Review 60(3), pp. $332-340$.

Ono, Yoshiyasu (1994): Money, Interest, and Stagnation - Dynamic Theory and Keynes's Economics. Oxford: Clarendon Press.

- (2001): "A Reinterpretation of Chapter 17 of Keynes's General Theory: Effective Demand Shortage under Dynamic Optimization". International Economic Review 42(1), pp. 207-236.

- (2015): Growth, Secular Stagnation and Wealth Preference. ISER Working Paper No. 946. Institute of Social and Economic Research, Osaka University.

Ono, Yoshiyasu and IshidA, Junichiro (2014): "On Persistent Demand Shortages: A Behavioral Approach". Japanese Economic Review 65(1), pp. 42-69.

Ono, Yoshiyasu, Ogawa, Kazuo, and Yoshida, Atsushi (2004): "Liquidity Preference and Persistent Unemployment with Dynamic Optimizing Agents". Japanese Economic Review 55 , pp. $355-371$.

Samuelson, Paul A. (1958): "An Exact Consumption-Loan Model of Interest with or without the Social Contrivance of Money". Journal of Political Economy 66(6), pp. 467-482.

Schmitt-Grohé, Stephanie and Uribe, Martín (2016): "Downward Nominal Wage Rigidity, Currency Pegs, and Involuntary Unemployment". Journal of Political Economy 124(5), pp. $1466-1514$.

- (2017): "Liquidity Traps and Jobless Recoveries". American Economic Journal: Macroeconomics 9(1), pp. 165-204.

Sidrauski, Miguel (1967): "Rational Choices and Patterns of Growth in a Monetary Economy". American Economic Review 57, pp. 534-544.

Smith, William T. (2001): "How Does the Spirit of Capitalism Affect Stock Market Prices?" Review of Financial Studies 14(4), pp. 1215-1232.

Summers, Lawrence H. (2013): "Conference Address". IMF Fourteenth Annual Research Conference in Honor of Stanley Fischer.

- (2014): "Reflections on the 'New Secular Stagnation Hypothesis"'. In: Secular Stagnation: Facts, Causes, and Cures. Ed. by R. Baldwin and C. Teulings. Vox eBook. Chap. 1, pp. $27-40$.

Tirole, Jean (1985): "Asset Bubbles and Overlapping Generations". Econometrica 53(6), pp. 1499-1528.

WeIzsÄCKer, Carl Christian von (2014): "Public Debt and Price Stability". German Economic Review 15(1), pp. 42-61. 
Zhou, Ge (2013): "Rational Equity Bubbles". Annals of Economics and Finance 14(2), pp. 511527.

- (2015): "The Spirit of Capitalism and Rational Bubbles". Macroeconomic Dynamics 20(6), pp. 1432-1457.

Zou, Heng-fu (1994): “'The Spirit of Capitalism' and Long-run Growth". European Journal of Political Economy 10(2), pp. 279-293. 